\title{
Estimating the effect of cutting data on surface roughness and cutting force during WC-Co turning with PCD tool using Taguchi design and ANOVA analysis
}

\author{
Wojciech Zębala $\cdot$ Robert Kowalczyk
}

Received: 28 February 2014 / Accepted: 8 September 2014 /Published online: 3 December 2014

(C) The Author(s) 2014. This article is published with open access at Springerlink.com

\begin{abstract}
The cutting of high hardness composite materials such as sintered carbides based on the cobalt is a challenge from a technological point of view. The paper presents the influence of cutting data $\left(v_{\mathrm{c}}, f, a_{\mathrm{p}}\right)$ and cobalt content in a work piece $(10,15$, and $25 \mathrm{wt} \%)$ on the turning process of WC-Co with polycrystalline diamond (PCD) tool. This study focuses on the main component of cutting force $F_{\mathrm{c}}$ and surface roughness, described by the roughness parameter Ra. The research plan, based on the Taguchi method, and variance analysis ANOVA were applied. Two types of experimental model, which describes turning process of sintered carbides based on the power function for three variables and polynomial functions as a modified method of the response surface methodology (RSM), were also presented.
\end{abstract}

Keywords Turning · Sintered carbides $\cdot$ PCD $\cdot$ Cutting force · Surface roughness

\section{Introduction}

The introduction of new standards in the field of environmental protection imposes the implementation of the new technology of super-hard material (such as sintered carbides WC-Co) machining [1]. Currently, most of these types of material are machined by grinding or electro-discharge (EDM) processes [2]. These processes are time-consuming and expensive, and contemporary companies find savings at every stage of production [3]. For the manufacture of WC-Co parts (for example, punches and construction parts), which are characterized

W. Zębala $(\bowtie) \cdot$ R. Kowalczyk

Production Engineering Institute, Mechanical Faculty, Cracow

University of Technology, Avenue Jana Pawła II 37, 31-864 Kraków,

Poland

e-mail: zebala@mech.pk.edu.pl by a high degree of hardness, high resistance to wear, and low surface roughness [4-7], alternative methods of production can be used. Machining with polycrystalline diamond (PCD) tools is one of the proposed solutions [2, 8-12]. PCD is characterized by a high degree of hardness, high thermal conductivity, as well as a low coefficient of friction in contact with the material being worked on and abrasion resistance $[8$, 13, 14].

At present, there is a lack of full knowledge about sintered carbides turning processes using PCD tools. The first studies in this area were described in the work [15]. The authors presented durability research of tools made of $\mathrm{cBN}$ and PCD, as well as silicon plates covered with chemical vapor deposition (CVD) diamond coating, soldered onto the sintered carbides holder, and surface quality after turning of WC-Co containing $27 \mathrm{wt} \% \mathrm{Co}$. The greatest value of surface roughness and the smallest cutting edge durability were obtained for PCD tools. In next studies, Belmonte et al. [16] determined the cutting data $\left(v_{\mathrm{c}}, f, a_{\mathrm{p}}\right)$ influence on the machining force value, wear tools, and working surface roughness while dry turning of WC-Co with $25 \mathrm{wt} \%$ Co content using CVD diamond brazed tools. The smallest machined surface roughness was observed in the case when the value of machining force $F_{\mathrm{c}}$ was below $35 \mathrm{~N}$. However, in the work, the impact of a cutting edge shape on machining process was not included. The work of Almeida et al. [17] can be complementary to these studies, in which the influence of the cutting edge shape (sharp, honed, and chamfered) of round cutting tool inserts made via direct diamond deposition on $\mathrm{Si}_{3} \mathrm{~N}_{4}$ ceramic substrate on the cutting force value while turning of WC-Co containing $25 \mathrm{wt} \% \mathrm{Co}$ was analyzed. The smallest machining force values and the best work piece finishing quality $(\mathrm{Ra}<0.2 \mu \mathrm{m})$ were registered for tools with the sharp edge tools.

In the separate study, conducted by Heo [18], the influence of WC particle size in the deformation zone on the wear of the PCD cutting tool while microcutting of wear-resistant 
tungsten carbides containing $22 \mathrm{wt} \%$ Co is presented. During machining, two chip formation types were received dependent on the shear angle. The thrust cutting forces presented a greater tendency to increase its value than the principal forces at an increase of $a_{\mathrm{p}}$ and $v_{\mathrm{c}}$ parameter values. The feed force showed a tendency to decrease its value with increasing of tool wear, which was a result of the cutting edge recession. In the publication, the influence of Co content in the material structure on the cutting forces was not described.

Cobalt content impact on the cutting process is partially described in Almeida et al.'s research [19]. Authors analyzed three types of dry turning of WC-Co with the WC grain size in the range of 2-6 $\mu \mathrm{m}$ and Co content (18-27 wt\%). The highest tool wear and cutting force values were obtained for material with the smallest Co content (18 wt\%). During studies, the highest values were observed for the thrust force and the smallest for the feed force (similar effect to grinding). It was also found that the higher Co content grade in the material structure induces an easy formation of a built-up edge (BUE) resulting in cutting force discontinuities. The critical force by which a tool destruction occurred had a value approximately $700 \mathrm{~N}$.

In previously described research, the effect of the adhesion process between the tool and cutting material in the sintered carbide turning process in the environment of the coolinglubricant substance has not been described. This impact was presented in the works [20,21]. The work [20] presents an effect of WC and Co additives in four kinds of cemented carbides on machinability and tool wear characteristics. In the studies of the materials of different Co contents $(10,13$, $19,25 \mathrm{wt} \%$ ), three different cooling conditions (dry, wet, and mist) were turned in. Research on the cooling effect of the cutting process showed that the smallest roughness values were obtained for turning with the application of the socalled oil mist. The influence of the Co content and WC grain sizes on cutting process by the effect of wear by tools confirms the results presented in $[18,19]$, while both dry turning and using coolant cutting forces increase have a linear character. The size of WC grains significantly influences on the tool wear when turning in the oil mist. With increasing a WC particle diameter in the material structure, the chip shape irregularities increase.

In the next publication [21], a comparison of the sintered carbides with $10 \mathrm{wt} \%$ Co content machining with PCD, cBN, and PcBN tools can be found. The smallest cutting insert wear was noted for PCD tools. The impact of cooling-lubricant substance on machining process is similar as in the work [20].

Almeida et al. [22] presented the results of the cutting force research during WC-Co (18 $\mathrm{wt} \% \mathrm{Co}$ ) machining for the two angular configurations of the tool: (i) neutral rake angle $0^{\circ}$, clearance angle $11^{\circ}$ and (ii) negative rake angle $-6^{\circ}$, clearance angle $6^{\circ}$. These results were not presented in
$[15,16,18,20]$. The study used CVD diamond-coated silicon tools as well as PCD tools. Tools with CVD coating were characterized by a greater durability, alike as described in [15]. In the case of PCD tools, a very clear tendency to the adhesion with work piece material was demonstrated, similarly as in [21], due to a high cobalt content in the cutting material $(18 \mathrm{wt} \% \mathrm{Co})$. The coefficients of friction between the tool and work piece material as the tangent to normal forces ratio $\left(F_{\mathrm{T}} / F_{\mathrm{N}}\right)$ were determined in the work too. For tools received by CVD method, the friction coefficient value was 0.7 after $180 \mathrm{~m}$ of cutting. In the case of PCD tools, the same friction coefficient value was appointed already after $70 \mathrm{~m}$ of cutting. For tools with diamond coating, an influence of angle configuration on the tools wear was not noticed. For the both configuration cases, the similar wear occurred.

Zhang et al. [23] compared the grinding of WC-Co with diamond and $\mathrm{cBN}$ grinding wheels as well as turning with PCD tools. In the case of turning, surface roughness had values in the range of $0.63-1.19 \mu \mathrm{m}$ at material removal rate (MRR) $2.37-18.7 \mathrm{~mm}^{3} / \mathrm{s}$, and grinding with diamond $/ \mathrm{cBN}$ grinding wheel roughness parameter was $0.017-0.1 \mu \mathrm{m}$ at MRR $0.667-2 \mathrm{~mm}^{3} / \mathrm{s}$.

The above presented examples do not describe accurate ranges of cutting data which can be used during sintered carbides turning with different cobalt contents. There is a lack of characteristics which describe the influence of tool cutting edge wear on cutting forces and surface roughness values. Available research shows the impact of cutting data on the machined surface quality only if two cutting parameters are permanent and the third is changeable. The percentage effect of individual cutting data on cutting force values has not been determined.

No comprehensive study of the super hard material turning, such as sintered carbides WC-Co with different Co contents, using PCD tools was the sole reason for undertaking the research described in this paper. An algorithm of experimental models building and optimization of WC-Co turning process was presented, which includes the research of cutting data $\left(v_{\mathrm{c}}, f, a_{\mathrm{p}}\right)$ as well as Co content in the material structure influence on the main cutting force component $F_{\mathrm{c}}$ and machined surface quality, described by Ra parameter. Cutting data optimization due to the minimization of the roughness parameter $\mathrm{Ra}$ and force $F_{\mathrm{c}}$ were conducted for the three types of sintered carbides: (i) $10 \mathrm{wt} \% \mathrm{Co}$ and $90 \mathrm{wt} \% \mathrm{WC}$; (ii) $15 \mathrm{wt} \% \mathrm{Co}, 0.15 \mathrm{wt} \% \mathrm{VC}$, and $84.85 \mathrm{wt} \% \mathrm{WC}$; and (iii) $25 \mathrm{wt} \% \mathrm{Co}, 0.15 \mathrm{wt} \% \mathrm{VC}$, and $74.85 \mathrm{wt} \% \mathrm{WC}$. Experimental research based on the Taguchi method and ANOVA variance analysis were described in Section 2 and results analysis in Section 3; however, experimental models building describing WC-Co turning process with PCD tool were presented in Section 4. 
Fig. 1 Algorithm of empirical model creation and optimization of WC-Co turning process. $S / N$ means signal-to-noise (Appendix 1)

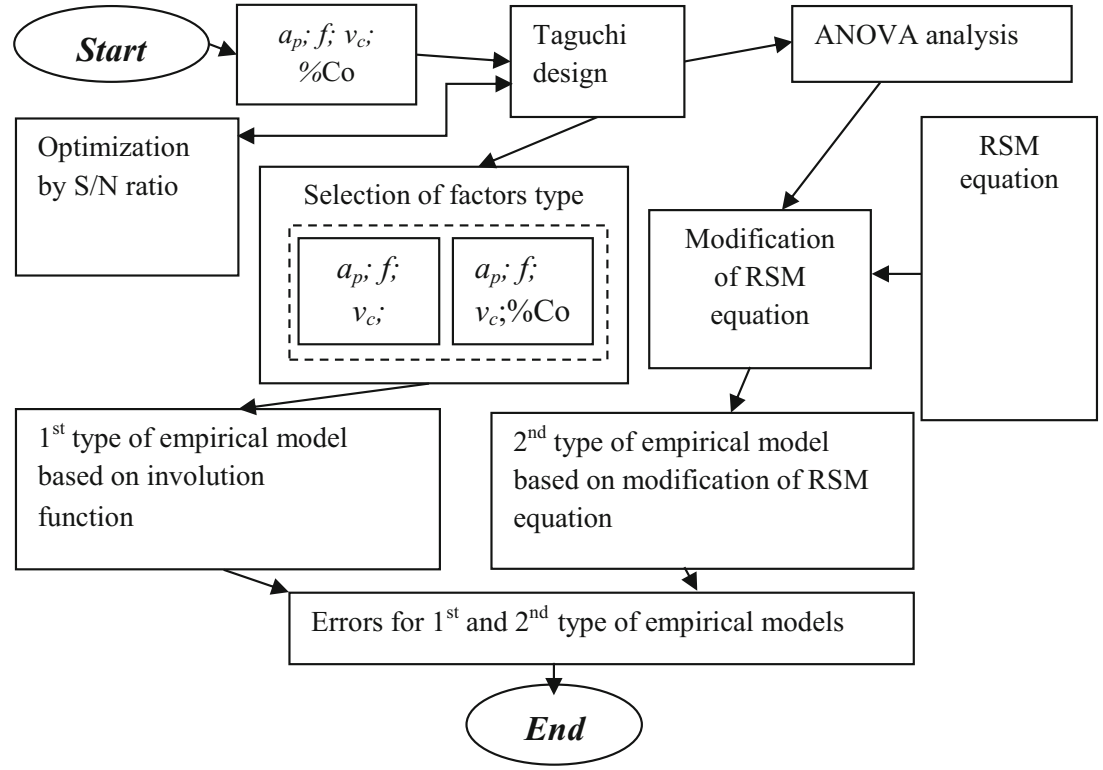

To study the influence of the cutting data $\left(v_{\mathrm{c}}, f, a_{\mathrm{p}}\right)$ and Co content in the material structure on the process of sintered carbides turning with PCD tools, the orthogonal array type of $\mathrm{L}_{9}$ was selected. The $\mathrm{L}_{9}$ array is characterized by the research plan for three variables of the cutting parameters at three different values, which corresponds to a total of nine research tests (Table 1). The cutting data values were divided into the appropriate levels and the numerical values $(1,2,3)$ were assigned to the particular level. The codes in the letters form (A, B, C) were set to the suitable cutting data. For the traditional plan of research, at least 27 research samples should be performed [24-26].

The selection of the cutting data for the sintered carbides turning was based on the ranges proposed by the manufacturer of the cutting tools, Mitsubishi company [32]:

- $a_{\mathrm{p}} \leq 0.5 \mathrm{~mm}$

- $f \leq 0.2 \mathrm{~mm} / \mathrm{rev}$

- $v_{\mathrm{c}}=(5-20) \mathrm{m} / \mathrm{min}$

The test stand, for recording of the main cutting force component $F_{\mathrm{c}}$, was built on the precision lathe with Kistler piezoelectric dynamometer, attached to the tool holder

Table 1 Cutting data, based on the manufacturer's catalogue, using notation of the $\mathrm{L}_{9}$ array

\begin{tabular}{llllll}
\hline Cutting data & Code & Unit & \multicolumn{2}{l}{ Levels } & \\
\cline { 3 - 6 } & & & 1 & 2 & 3 \\
\hline Feed $f$ & $\mathrm{~A}$ & $\mathrm{~mm} / \mathrm{rev}$ & 0.105 & 0.153 & 0.211 \\
Cutting speed $v_{\mathrm{c}}$ & $\mathrm{B}$ & $\mathrm{m} / \mathrm{min}$ & 10 & 15 & 20 \\
Depth of cut $a_{\mathrm{p}}$ & $\mathrm{C}$ & $\mathrm{mm}$ & 0.2 & 0.35 & 0.5 \\
\hline
\end{tabular}


Fig. 2 Test stand for recording of the main cutting force: a shaft made of WC-Co (1), insert type of TNGA 160408 with PCD edge (2), holder (3), and dynamometer (4); $\mathbf{b}$ dimensions of the TNGA 160408 insert
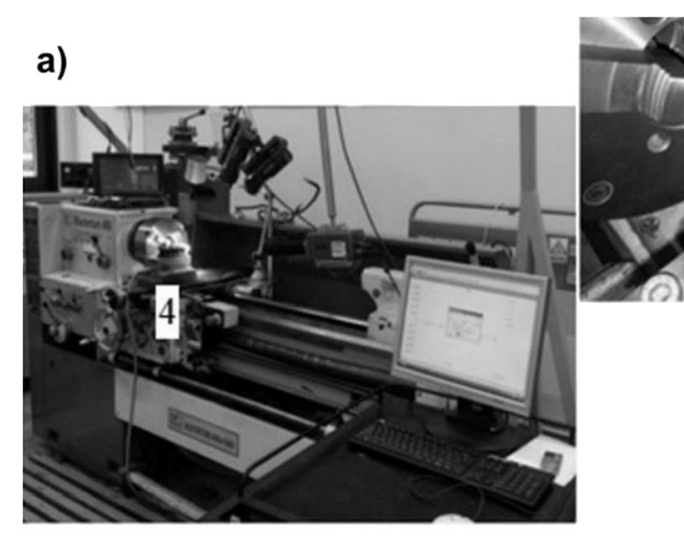

\section{(2)}

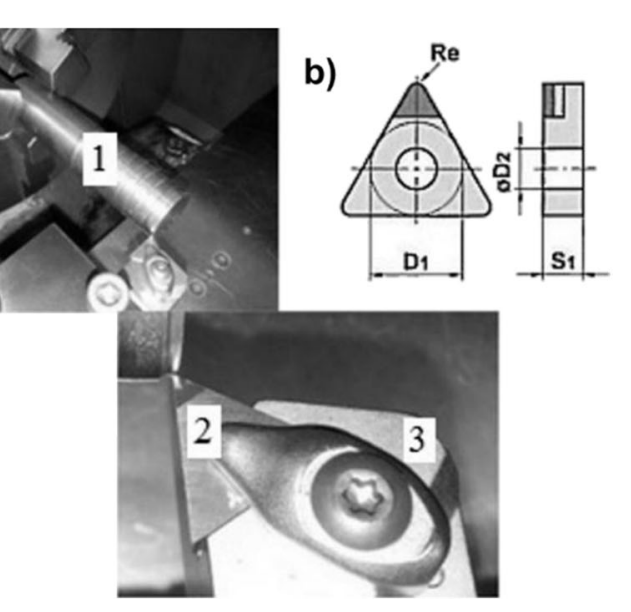

(Fig. 2). Measurement of the surface roughness was performed using the Taylor Hobson profilometer.

In the study, the Mitsubishi triangular inserts with one edge of the polycrystalline diamond PCD type of MD220 were used. The dimensions of the TNGA 160408 type inserts were $D_{1}=9.525 \mathrm{~mm}, S_{1}=4.76 \mathrm{~mm}, R_{\mathrm{e}}=0.8 \mathrm{~mm}$, and $D_{2}=3.81 \mathrm{~mm}$ (Fig. 2b). The characteristics and properties of each work piece material are described in Table 2.

2.3 Results of the recorded values of the main cutting force component $\boldsymbol{F}_{\mathrm{c}}$ and surface roughness parameter Ra for the work piece materials with different contents of $\mathrm{Co}$

\subsubsection{Results of the recorded values of the cutting force $F_{c}$ for the first $(25 \mathrm{wt} \% \mathrm{Co})$ and second $(15 \mathrm{wt} \% \mathrm{Co})$ shafts}

Recorded values of the cutting force $F_{\mathrm{c}}$ for the first and second shafts with content 25 and $15 \mathrm{wt} \%$ Co together with calculated values of the $\mathrm{S} / \mathrm{N}$ ratio according to the larger-the-better (Appendix 1, Eq. 22) criterion are shown in Table 3.

Based on the $\mathrm{S} / \mathrm{N}$ ratio, the cutting data for the lowest values of the cutting force $F_{\mathrm{c}}$ was indicated. For both materials, the lowest values of the cutting force $F_{\mathrm{c}}$ were obtained at the same cutting data:

- $f=0.105 \mathrm{~mm} / \mathrm{rev}$

- $v_{\mathrm{c}}=10 \mathrm{~m} / \mathrm{min}$

- $a_{\mathrm{p}}=0.2 \mathrm{~mm}$
Simultaneously, an increase of the cutting force $F_{\mathrm{c}}$ value for machining of the work piece with a lower content of Co in the material structure was noticed.

Results of the measured values of the surface roughness parameter Ra for the first and second shafts with content 25 and $15 \mathrm{wt} \%$ Co with the calculated values of the $\mathrm{S} / \mathrm{N}$ ratio (criterion larger-the-better) are shown in Table 4. For the surface roughness parameter $\mathrm{Ra}$, there is a similar situation like in the case of the recorded values of the cutting force $F_{\mathrm{c}}$. In the case of materials with two different contents of $\mathrm{Co}$, the smallest $\mathrm{Ra}$ parameter values for the same cutting data were obtained:

- $f=0.105 \mathrm{~mm} / \mathrm{rev}$

- $v_{\mathrm{c}}=15 \mathrm{~m} / \mathrm{min}$

- $a_{\mathrm{p}}=0.5 \mathrm{~mm}$

It was also revealed that after turning of the shaft with a lower content of $\mathrm{Co}$, the larger values of the surface roughness described by the Ra parameter were obtained.

Scanning electron micrographs (SEM) of chips, obtained during machining of the first and second shafts for the lowest

\subsubsection{Results of the measured values of the surface roughness parameter Ra for the first (25 wt\% Co) and second (15 wt\% Co) shafts}

Table 2 Characteristics and properties of the work piece materials

\begin{tabular}{llllll}
\hline Number of tested shaft & Chemical composition & Quantity Co \% & Density g/cm ${ }^{3}$ & Hardness HV $_{10}$ & Hardness HR $_{\mathrm{A}}$ \\
\hline 1st shaft & $25 \% \mathrm{Co}, 0.15 \% \mathrm{VC}, 74.85 \% \mathrm{WC}$ & 25 & 13.1 & 950 & 85.4 \\
2nd shaft & $15 \% \mathrm{Co}, 0.15 \% \mathrm{VC}, 84.85 \% \mathrm{WC}$ & 15 & 14 & 1200 & 88.2 \\
3rd shaft & $10 \% \mathrm{Co}, 90 \% \mathrm{WC}$ & 10 & 14.75 & 1610 & 91.9 \\
\hline
\end{tabular}


Table 3 Recorded values of the main cutting force $F_{\mathrm{c}}$ for the first and second shafts with calculated $\mathrm{S} / \mathrm{N}$ ratio values (criterion larger-the-better)

\begin{tabular}{llllllll}
\hline $\begin{array}{l}\text { Surface } \\
\text { number }\end{array}$ & A & B & C & $\begin{array}{l}F_{\mathrm{c}}(\mathrm{N}) \\
\text { shaft no. } 1\end{array}$ & S/N & $\begin{array}{l}F_{\mathrm{c}}(\mathrm{N}) \\
\text { shaft no. 2 }\end{array}$ & $\mathrm{S} / \mathrm{N}$ \\
\hline 1 & 3 & 3 & 3 & 435.7 & -52.78 & 414.5 & -52.35 \\
2 & 1 & 2 & 3 & 274.9 & -48.78 & 311.1 & -49.86 \\
3 & 2 & 1 & 3 & 318.4 & -50.06 & 361.0 & -51.15 \\
4 & 2 & 2 & 2 & 264.0 & -48.43 & 284.2 & -49.07 \\
5 & 3 & 1 & 2 & 374.6 & -51.47 & 323.9 & -50.21 \\
6 & 1 & 3 & 2 & 278.5 & -48.90 & 264.4 & -48.45 \\
7 & 1 & 1 & 1 & 181.0 & $-\mathbf{4 5 . 1 5}$ & 196.2 & $\mathbf{- 4 5 . 8 5}$ \\
8 & 2 & 3 & 1 & 196.0 & -45.85 & 219.3 & -46.82 \\
9 & 3 & 2 & 1 & 222.8 & -46.96 & 222.8 & -46.96 \\
\hline
\end{tabular}

The entries in bold mean the maximum values of $\mathrm{S} / \mathrm{N}$ ratio (criterion larger-the-better)

values of $F_{\mathrm{c}}$ and the lowest surface roughness Ra, are presented in Fig. 3.

\subsubsection{Results of the recorded values of the cutting force $F_{c}$ and the measured values of the surface roughness $R a$ for the third shaft with content $10 \mathrm{wt} \% \mathrm{Co}$}

Recorded values of the cutting force $F_{\mathrm{c}}$ and measured values of the surface roughness parameter Ra for the third shaft with content $10 \mathrm{wt} \%$ Co are shown in Table 5.

The results for only three research samples of the shaft with content of $10 \mathrm{wt} \%$ Co are presented. For other surfaces, the violent increase of the cutting edge wear of the TNGA 160408 inserts type for the depth of cut larger than $0.2 \mathrm{~mm}$ occurred. These situations are illustrated in Fig. 4 which presents the chips with irregular shape and large size. The scales in the figures, presented in the form of horizontal lines mean the following: $1-5 \mathrm{~mm}, 2-500 \mu \mathrm{m}$, and $3-1000 \mu \mathrm{m}$.

Table 4 Results of the measured values of the surface roughness parameter $\mathrm{Ra}$ for the first and second shafts with calculated values of the $\mathrm{S} / \mathrm{N}$ ratio (criterion larger-the-better)

\begin{tabular}{llllllll}
\hline $\begin{array}{l}\text { Surface } \\
\text { number }\end{array}$ & A & B & C & $\begin{array}{l}\text { Ra }(\mu \mathrm{m}) \\
\text { shaft no. } 1\end{array}$ & S/N & $\begin{array}{l}\text { Ra }(\mu \mathrm{m}) \\
\text { shaft no. } 2\end{array}$ & S/N \\
\hline 1 & 3 & 3 & 3 & 2.10 & -6.45 & 1.90 & -5.56 \\
2 & 1 & 2 & 3 & 0.63 & $\mathbf{4 . 0 4}$ & 0.92 & $\mathbf{0 . 7 1}$ \\
3 & 2 & 1 & 3 & 0.93 & 0.63 & 1.22 & -1.70 \\
4 & 2 & 2 & 2 & 1.24 & -1.84 & 1.21 & -1.66 \\
5 & 3 & 1 & 2 & 1.99 & -5.98 & 1.99 & -5.96 \\
6 & 1 & 3 & 2 & 1.18 & -1.45 & 1.00 & -0.004 \\
7 & 1 & 1 & 1 & 1.26 & -2.01 & 1.08 & -0.73 \\
8 & 2 & 3 & 1 & 1.55 & -3.80 & 1.66 & -4.40 \\
9 & 3 & 2 & 1 & 2.01 & -6.06 & 2.67 & -8.53 \\
\hline
\end{tabular}

The entries in bold mean the maximum values of $\mathrm{S} / \mathrm{N}$ ratio (criterion larger-the-better)
2.4 Analysis of variance ANOVA for the first and second shafts with content of 25 and $15 \mathrm{wt} \%$ Co

The analysis of variance, better known as ANOVA analysis, allows to determine the influence of the quality factor level on the measurable characteristics of the research object $[24,26$, 27, 29-31]. In the research, the ANOVA analysis was used to indicate the percentage influence of the particular cutting data on the main cutting force $F_{\mathrm{c}}$ values and the surface roughness described by the parameter Ra after the sintered carbides turning.

An explanation of functions, which were used in construction of a table for the analysis of variance ANOVA, is presented in Appendix 2. The numbers of degrees of freedom for each source of variability results are presented in Appendix 2.

The analysis of variance ANOVA of the cutting data percentage influence on the cutting force $F_{\mathrm{c}}$ for the first shaft with $25 \mathrm{wt} \%$ Co is shown in Table 6, while the results for the second shaft with $15 \mathrm{wt} \%$ Co are shown in Table 7.

The depth of cut has the greatest influence on the cutting force $F_{\mathrm{c}}$ value while turning of the first shaft. The cutting speed $v_{\mathrm{c}}$ has a lower influence, and the feed $f$ has a very small effect, which is described in Table 6.

In the case of the second shaft, the depth of cut also has the greatest influence on the cutting force $F_{\mathrm{c}}$. The feed has less influence, and the cutting speed has the least influence (Table 7). Figure 5a, b shows interactions of the individual cutting data on the main cutting force $F_{\mathrm{c}}$ for materials with content 15 and $25 \mathrm{wt} \%$ Co. The individual graphs in Fig. 5a, b show suitable levels of research factor interaction with the various levels of the other two factors' influence on the cutting force $F_{\mathrm{c}}$ values. When the value of the cutting speed equals $10 \mathrm{~m} / \mathrm{min}$, with increasing values of the feed, more values of the main cutting force $F_{\mathrm{c}}$ are generated. When the intermediate cutting speed equals $15 \mathrm{~m} / \mathrm{min}$, the opposite situation occurs compared to the first cutting-level speed. With an increase in the feed, a decrease of values in the cutting force $F_{\mathrm{c}}$ is observed. At the highest values of the feed, the highest values of the cutting force $F_{\mathrm{c}}$ are generated.

The analysis of variance ANOVA of the percentage influence on the surface roughness described by the Ra parameter for the first shaft with $25 \%$ Co is shown in Table 8, while the results for the second shaft with $15 \mathrm{wt} \%$ Co are shown in Table 9.

The cutting speed has the greatest influence on the surface roughness for the first shaft, the effect of the feed and depth of cut is very small.

In the case of the second shaft, a similar (as for the first shaft) effect of the cutting data on the surface roughness described by the Ra parameter was noticed. The cutting speed has the least impact. Figure $6 a, b$ shows the interaction of the appropriate cutting data on the surface roughness parameter $\mathrm{Ra}$ for the materials with content 25 and $15 \mathrm{wt} \% \mathrm{Co}$. 
Fig. 3 SEM views of chips, obtained during machining of the: a the first shaft for the lowest values of $F_{\mathrm{c}}, \mathbf{b}$ the second shaft for the lowest values of $F_{\mathrm{c}}$, $\mathbf{c}$ the first shaft for the lowest surface roughness $\mathrm{Ra}$, and $\mathbf{d}$ the second shaft for the lowest surface roughness $\mathrm{Ra}$

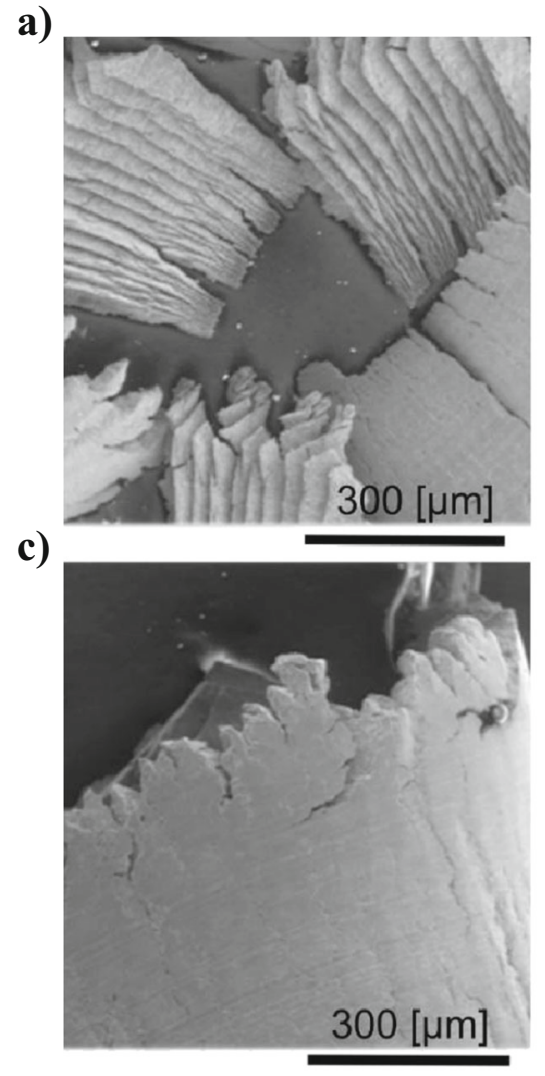

b)

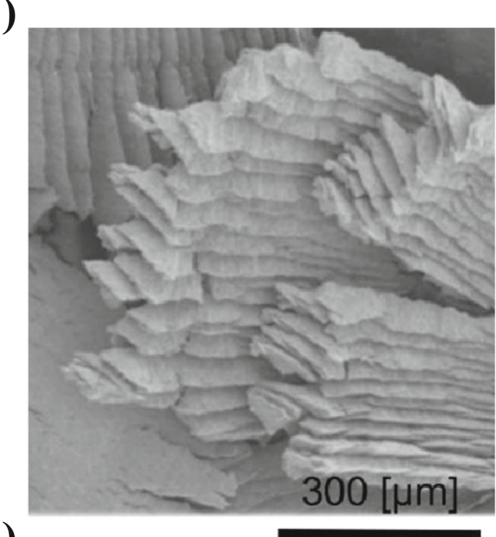

d)

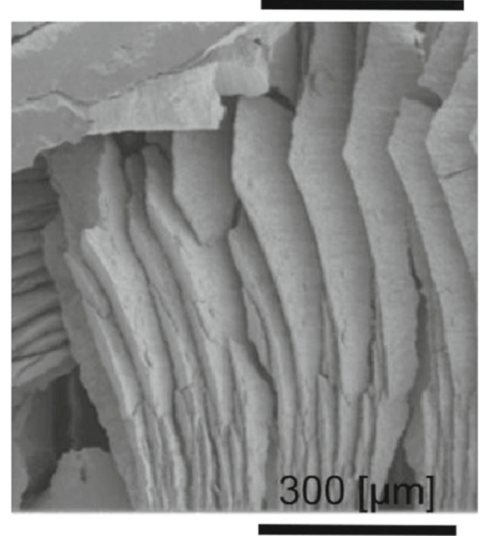

\section{Analysis of results}

3.1 Analysis of the measured values of the cutting force $\boldsymbol{F}_{\mathrm{c}}$

The main effects of the cutting data on values of the cutting force $F_{\mathrm{c}}$ for the second shaft with content $15 \mathrm{wt} \%$ Co are shown in Fig. $7 \mathrm{a}$ and for the first shaft with content $25 \mathrm{wt} \% \mathrm{Co}$ are shown in Fig. 7b.

For the first and second shafts, there are similar characteristics of the cutting data influence on the average values of the cutting force $F_{\mathrm{c}}$ for appropriate levels of the cutting data. The cutting force $F_{\mathrm{c}}$ also increases with higher values of feed and depth of cut. The cutting speed has a different trend than feed and depth of cut. For the intermediate value of the cutting speed $(15 \mathrm{~m} / \mathrm{min})$, the lowest value of the cutting force $F_{\mathrm{c}}$ was recorded.

During the analysis of the Co content influence on the value of the cutting force $F_{\mathrm{c}}$, the following relationship was

Table 5 Recorded values of the cutting force $F_{\mathrm{c}}$ and surface roughness Ra for the third shaft

\begin{tabular}{llllll}
\hline Surface number & $f(\mathrm{~mm} / \mathrm{rev})$ & $v_{\mathrm{c}}(\mathrm{m} / \mathrm{min})$ & $a_{\mathrm{p}}(\mathrm{mm})$ & $F_{\mathrm{c}}(\mathrm{N})$ & $\mathrm{Ra}(\mu \mathrm{m})$ \\
\hline 1 & 0.105 & 10 & 0.2 & 178.8 & 1.39 \\
2 & 0.153 & 20 & 0.2 & 194.5 & 1.90 \\
3 & 0.211 & 15 & 0.2 & 204.1 & 1.39 \\
\hline
\end{tabular}

observed: the lower content of $\mathrm{Co}$ in the material structure, the greater value of the cutting force $F_{\mathrm{c}}$ for the same cutting data, but only for surfaces 1, 5, and 6, as shown in Fig. 8.

3.2 Analysis of the measured values of the surface roughness parameter Ra

The main effects of the cutting data on values of the surface roughness parameter $\mathrm{Ra}$ for the second shaft with content $15 \mathrm{wt} \%$ Co are shown in Fig. 9a and for the first shaft with content $25 \mathrm{wt} \%$ Co are shown in Fig. 9b.

In the case of the average influence of the particular cutting data on the measured values of the surface roughness described by the Ra parameter, other characteristics than the results for the main components of the cutting force $F_{\mathrm{c}}$ are noticed. On the basis of the charts in Fig. 9a, b, a trend showing that the increased value of the feed followed by deterioration of the surface roughness by increasing the $\mathrm{Ra}$ parameter is noticed. For the depth of cut, the opposite situation than for the feed is noticed. With the depth of cut, the surface quality improves. Two different characteristics are noticed for the cutting speed. In the case of the second shaft, the smallest value of the surface roughness for the average value of the cutting speed was obtained, and in the case of the first shaft, the smallest value of the surface roughness for the first level of the cutting speed $(10 \mathrm{~m} / \mathrm{min})$ was obtained. The 
Fig. 4 Views of chips obtained for the third shaft: a $f=0.211 \mathrm{~mm} /$ rev, $v_{\mathrm{c}}=20 \mathrm{~m} / \mathrm{min}, a_{\mathrm{p}}=0.5 \mathrm{~mm}$; needle chips or irregular short discontinuous chips; $\mathbf{b} f=$

$0.105 \mathrm{~mm} / \mathrm{rev}, v_{\mathrm{c}}=15 \mathrm{~m} / \mathrm{min}, a_{\mathrm{p}}=$ $0.5 \mathrm{~mm}$; needle chips, amorphous short discontinuous chips, loose arc chips, and elemental chips; c $f=0.153 \mathrm{~mm} / \mathrm{rev}, v_{\mathrm{c}}=15 \mathrm{~m} / \mathrm{min}$, $a_{\mathrm{p}}=0.35 \mathrm{~mm}$; needle chips, amorphous long discontinuous chips; and $\mathbf{d} f=0.211 \mathrm{~mm} / \mathrm{rev}, v_{\mathrm{c}}=$ $10 \mathrm{~m} / \mathrm{min}, a_{\mathrm{p}}=0.35 \mathrm{~mm}$; elemental chips, loose arc chips, and amorphous chips a)

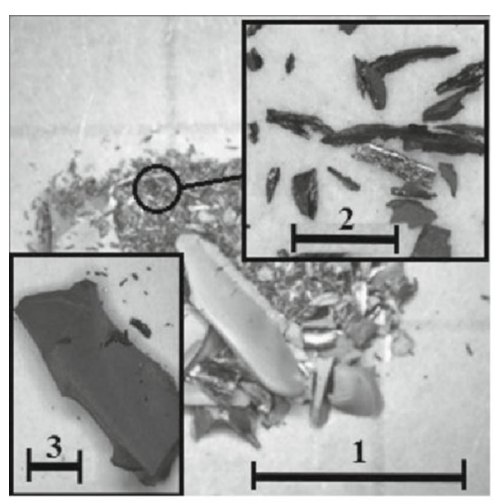

c)

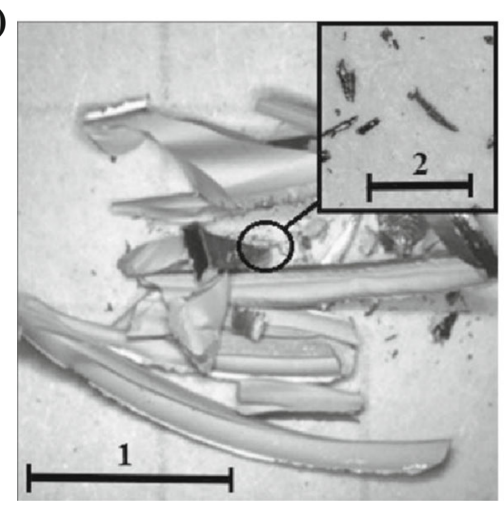

b)

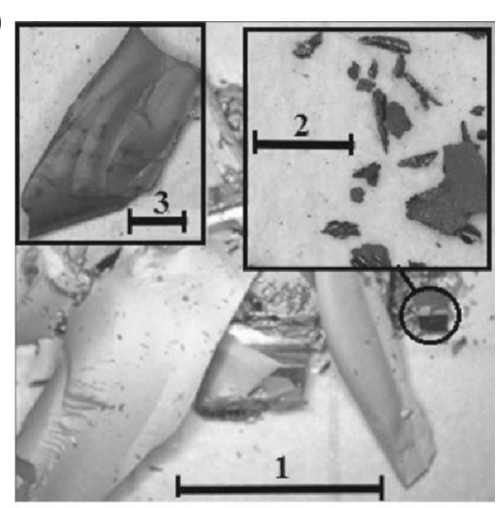

d)

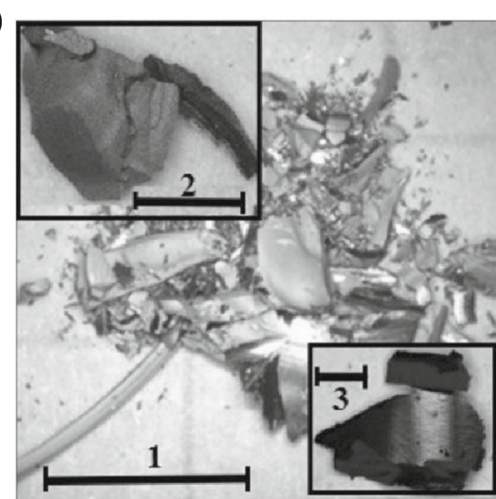

effects of the Co content in the material structure on the values of the surface roughness for the same cutting data are very different. For the first, fourth, sixth, and seventh surfaces with a lower content of $\mathrm{Co}$, better quality surfaces were achieved (Fig. 10).

\subsection{Analysis of the influence of the Co content in the work} piece material on the obtained values of the cutting force $\boldsymbol{F}_{\mathrm{c}}$ and surface roughness

For the comparison of the effects of the Co content in the material structure on the cutting force $F_{\mathrm{c}}$ and the values of the surfaces roughness, only three surfaces

Table 6 Analysis of variance (ANOVA) of the cutting data percentage influence on the cutting force $F_{\mathrm{c}}$ for the first shaft

\begin{tabular}{llrrrrr}
\hline Parameter & $\begin{array}{l}\text { Degrees of } \\
\text { freedom }\end{array}$ & SS & MS & $F$ & $P \%$ & $\alpha$ \\
\hline$v_{\mathrm{c}}$ & 2 & 17332.78 & 8666.4 & 27.66 & 30.38 & 0.01 \\
$f$ & 2 & 3989.07 & 1994.5 & 6.37 & 6.11 & 0.01 \\
$a_{\mathrm{p}}$ & 2 & 33035.71 & 16517.9 & 52.73 & 58.94 & 0.01 \\
Error & 2 & 626.56 & 313.3 & & 4.55 & \\
Total & 8 & 54984.12 & & & 100 & \\
\hline
\end{tabular}

for the particular shafts for the same cutting data were used (Fig. 11a, b). The cutting force $F_{\mathrm{c}}$ for the other research samples for the third material has not been recorded, due to extremely severe wear of the tools, as described earlier in Section 2.3.3.

It was noticed that for the low Co content (10 wt $\%)$, the lower values of the cutting force $F_{\mathrm{c}}$ were generated and the worse quality of the surface was observed. The smaller values of the cutting force $F_{\mathrm{c}}$ for the third shaft for the same cutting data can be a result of the smaller adhesion effect between the work piece and cutting tool. The large values of the surface roughness for the third shaft are a result of high hardness of the work piece materials.
Table 7 Analysis of variance (ANOVA) of the cutting data percentage influence on the cutting force $F_{\mathrm{c}}$ for the second shaft

\begin{tabular}{llrrrrr}
\hline Parameter & $\begin{array}{l}\text { Degrees of } \\
\text { freedom }\end{array}$ & \multicolumn{1}{l}{ SS } & MS & $F$ & $P \%$ & $\alpha$ \\
\hline$v_{\mathrm{c}}$ & 2 & 1188.7 & 594.3 & 2.77 & 1.84 & 0.01 \\
$f$ & 2 & 5992.2 & 2996.1 & 13.95 & 13.52 & 0.01 \\
$a_{\mathrm{p}}$ & 2 & 33527.3 & 16763.7 & 78.08 & 80.45 & 0.01 \\
Error & 2 & 429.4 & 214.7 & & 4.17 & \\
Total & 8 & 41137.6 & & & 100 & \\
\hline
\end{tabular}


Fig. 5 Interaction of appropriate levels of the cutting data on the cutting force $F_{\mathrm{c}}$ for $\mathbf{a}$ the first shaft with content $25 \mathrm{wt} \% \mathrm{Co}$ and $\mathbf{b}$ the second shaft with content $15 \mathrm{wt} \%$ Co

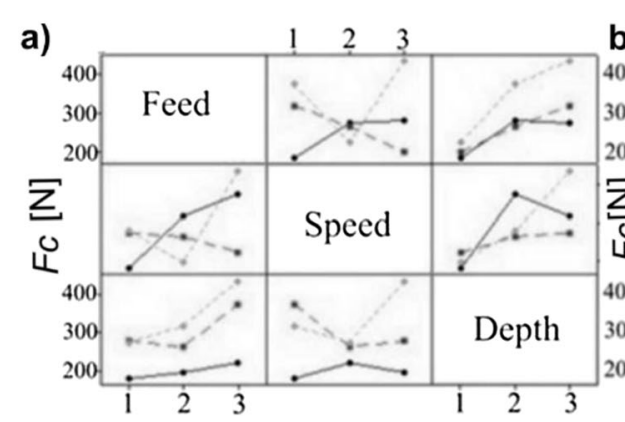

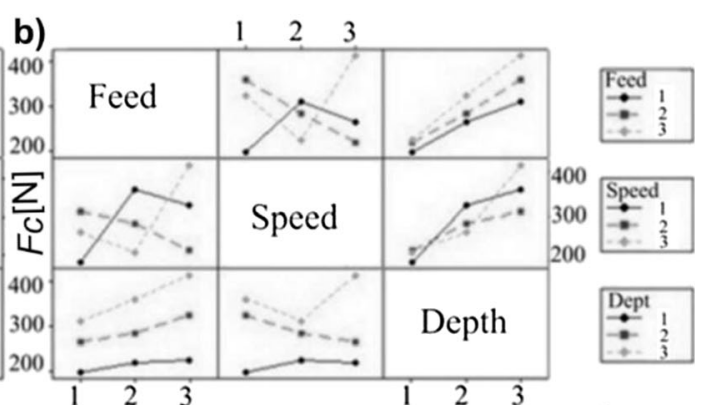

Table 8 Analysis of variance (ANOVA) of the cutting data percentage influence on the surface roughness Ra for the first shaft

\begin{tabular}{lllllll}
\hline Parameter & Degrees of freedom & SS & MS & $F$ & $P \%$ & $\alpha$ \\
\hline$v_{\mathrm{c}}$ & 2 & 1.69 & 0.85 & 36.54 & 77.41 & 0.05 \\
$f$ & 2 & 0.16 & 0.08 & 3.39 & 5.34 & 0.05 \\
$a_{\mathrm{p}}$ & 2 & 0.23 & 0.11 & 4.97 & 8.64 & 0.05 \\
Error & 2 & 0.05 & 0.02 & & 8.59 & \\
Total & 8 & 2.13 & & & 100 & \\
\hline
\end{tabular}

Table 9 Analysis of variance (ANOVA) of the cutting data percentage influence on the surface roughness $\mathrm{Ra}$ for the second shaft

\begin{tabular}{lllllll}
\hline Parameter & Degrees of freedom & SS & MS & $F$ & $P \%$ & $\alpha$ \\
\hline$v_{\mathrm{c}}$ & 2 & 2.20 & 1.10 & 27.58 & 78.39 & 0.01 \\
$f$ & 2 & 0.04 & 0.02 & 0.55 & 4.55 & 0.01 \\
$a_{\mathrm{p}}$ & 2 & 0.38 & 0.19 & 4.78 & 11.15 & 0.01 \\
Error & 2 & 0.08 & 0.04 & & 5.89 & \\
Total & 8 & 2.70 & & & 100 & \\
\hline
\end{tabular}

\section{Empirical models, describing WC-Co turning process with PCD tools}

\subsection{First type of experimental model based on the power} function

The measured values of the cutting force $F_{\mathrm{c}}$ shown in Table 3 and the measured values of the surface roughness described by the Ra parameter shown in Table 4 for the sintered carbides turning with PCD tools usage can be used for the equations' determination, which allow the description of the turning process. Two methods of the empirical model of WC-Co turning process are shown in the paper. The first type of the empirical model for the first shaft is based on the power function, model type I [30, 31, 33].

Any of investigated phenomena can be described by the following equation:

$Y=a_{1} \times x_{1}^{a_{2}} \times x_{2}^{a_{2}} \times \cdots \times x_{i}^{a_{i}}$

where $Y$ is a parameter value, describing the investigated physical phenomenon, i.e., the cutting force $F_{c} ; a_{1}, a_{2}, \ldots, a_{i}$
Fig. 6 Interaction of appropriate levels of the cutting data on the surface roughness parameter $\mathrm{Ra}$ for $\mathbf{a}$ the first shaft and $\mathbf{b}$ the second shaft

Fig. 7 Main effects of the cutting data on the cutting force $F_{\mathrm{c}}$ for a the second shaft and $\mathbf{b}$ the first shaft
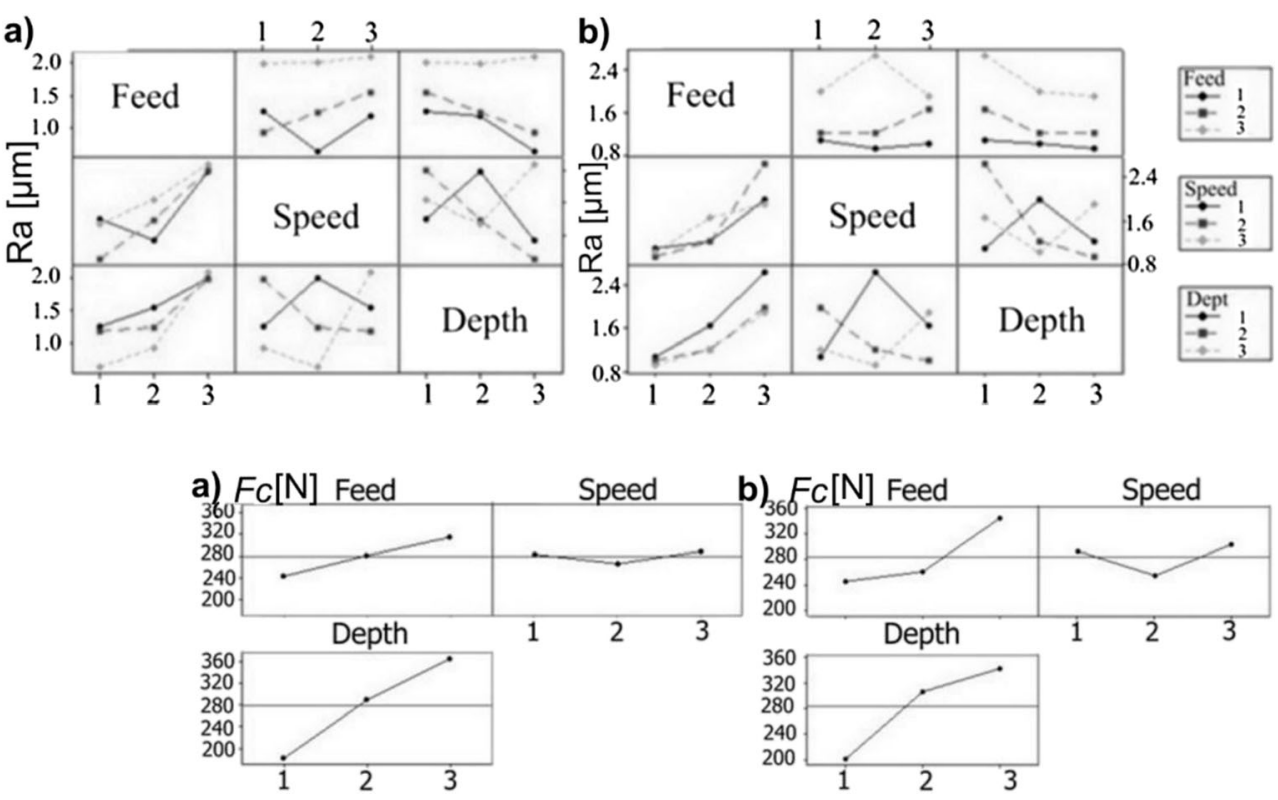


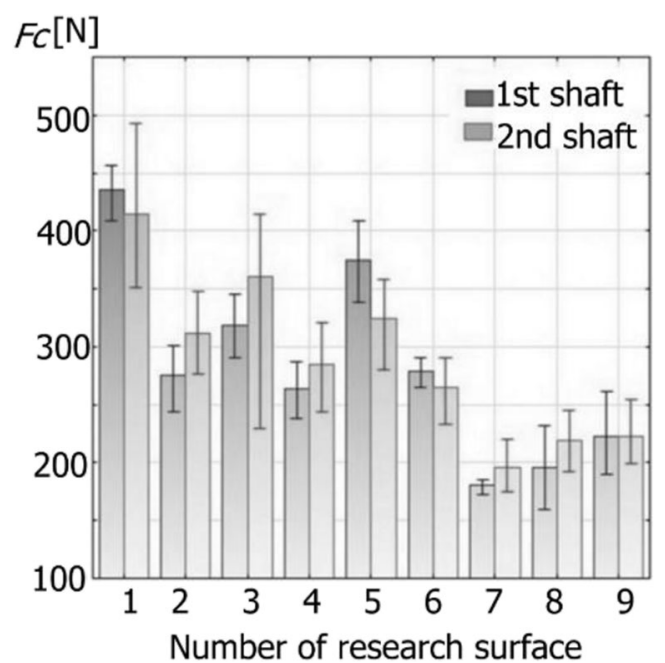

Fig. 8 Comparison of the Co content influence on the main cutting force for the first and second shafts

are constant coefficients; and $x_{1}, x_{2}, \ldots, x_{i}$ are factors, which influence the investigated parameter.

The cutting force $F_{\mathrm{c}}$ can be expressed by Eq. (2):

$F_{\mathrm{c}}=a \times f^{b} \times v_{\mathrm{c}}{ }^{c} \times a_{\mathrm{p}}{ }^{d}$

where $a, b, c$, and $d$ are constants; and $v_{\mathrm{c}}, f$, and $a_{\mathrm{p}}$ are independent variables representing suitable cutting data based on Eq. (1).

Equation (2), which describes (in symbolic) estimated value of the force $F_{\mathrm{c}}$, can be linearized by finding the logarithm (3):

$\log \left(F_{\mathrm{c}}\right)=\log (a)+b \log (f)+c \log \left(v_{\mathrm{c}}\right)+d \log \left(a_{\mathrm{p}}\right)$

To facilitate the equation notation (3), a new equation was written (4):

$$
\begin{aligned}
\log \left(F_{c}\right) & =Y ; \log (a)=A_{0} ; b=A_{1} ; \log (f)=X_{1} ; c \\
& =A_{2} ; \log \left(v_{\mathrm{c}}\right)=X_{2} ; d=A_{3} ; \log \left(a_{\mathrm{p}}\right)=X_{3}
\end{aligned}
$$

Using the above new variables, the Eq. (3) takes the form (5):

$$
Y=A_{0}+A_{1} X_{1}+A_{2} X_{2}+A_{3} X_{3}
$$

\section{$\operatorname{Ra}[\mu \mathrm{m}]$}

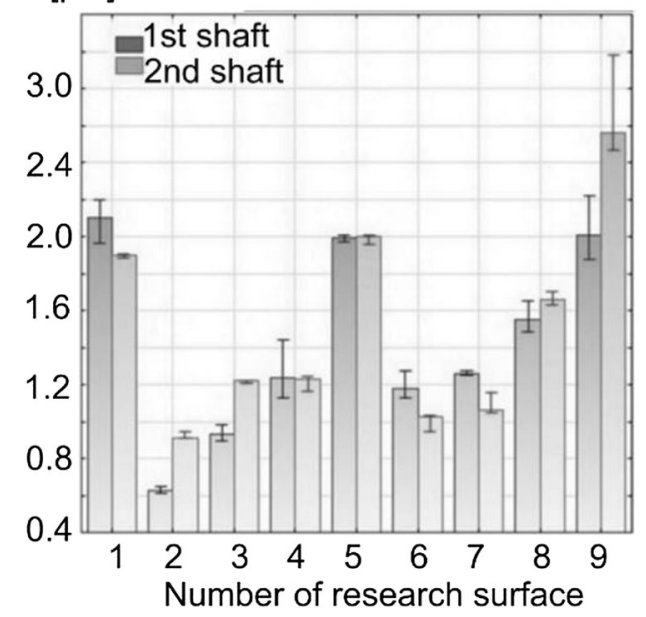

Fig. 10 Comparison of the Co content influence on the surface roughness parameter Ra for the first and second hafts

The values of $X_{1}, X_{2}$, and $X_{3}$ are assumed (independent factors, values of cutting data), and the $Y$ value is measured, i.e., value of the cutting force $F_{\mathrm{c}}$ (the parameter depends on $X_{i}$ values and values of constant factors).

Equation (5) can represent a mathematical notation of the machining process or any other physical phenomenon. Equation (5) can be used to investigate the influence of individual variables on the output investigated phenomenon. In the case of this work, the cutting force $F_{\mathrm{c}}$ or surface roughness Ra are these values.

Equation (5) with the appropriate values of the cutting force $F_{\mathrm{c}}$ and cutting data $\left(v_{\mathrm{c}}, f, a_{\mathrm{p}}\right)$ was put into the Wolfram Mathematica 7 environment (system of equations with four unknowns). After calculations, the constant coefficients $a, b$, $c$, and $d$ were obtained.

The final equations describing the cutting force and surface roughness for variable cutting data for the first shaft with content of $25 \mathrm{wt} \% \mathrm{Co}$, taking into account the set of the calculated coefficients $(a, b, c, d)$, have the forms $(6,7)$ :

$$
F_{\mathrm{c}}=190.499 \times v_{\mathrm{c}}^{0.563408} \times f^{0.217297} \times a_{\mathrm{p}}^{0.753408}
$$

$\mathrm{Ra}=0.0512948 \times v_{\mathrm{c}}^{1.47836} \times f^{0.55769} \times a_{\mathrm{p}}^{-0.217913}$
Fig. 9 Main effects of the cutting data on the surface roughness parameter $\mathrm{Ra}$ for a the second shaft and $\mathbf{b}$ the first shaft

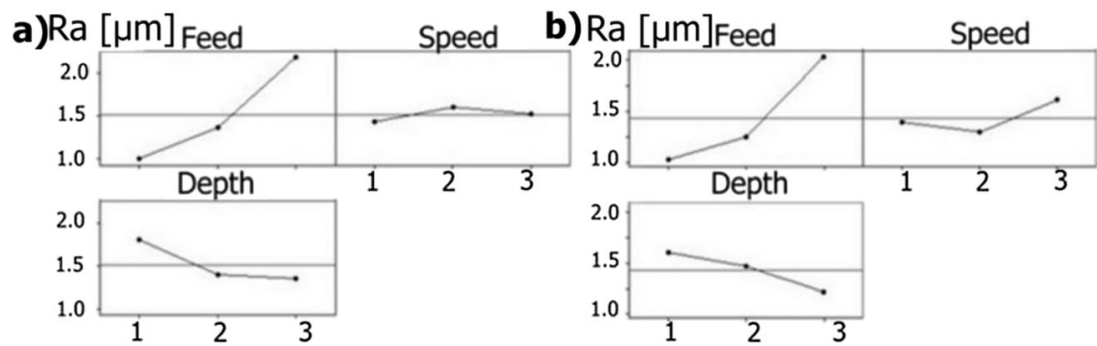



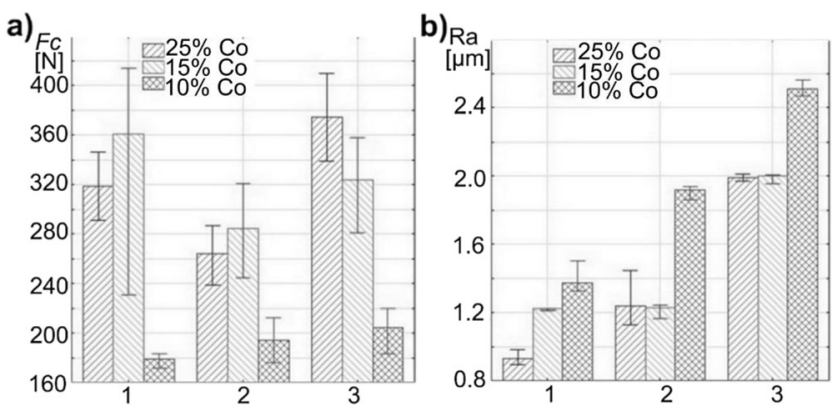

Fig. 11 Influence of Co content on a cutting force $F_{\mathrm{c}}$, $\mathbf{b}$ surface roughness Ra (1) $f=0.105 \mathrm{~mm} / \mathrm{rev} ; v_{\mathrm{c}}=10 \mathrm{~m} / \mathrm{min} ; a_{\mathrm{p}}=0.2 \mathrm{~mm}$; (2) $f=$ $0.153 \mathrm{~mm} / \mathrm{rev} ; v_{\mathrm{c}}=20 \mathrm{~m} / \mathrm{min} ; a_{\mathrm{p}}=0.2 \mathrm{~mm}$; (3) $f=0.211 \mathrm{~mm} / \mathrm{rev} ; v_{\mathrm{c}}=$ $15 \mathrm{~m} / \mathrm{min} ; a_{\mathrm{p}}=0.2 \mathrm{~mm}$

For the second shaft, Eq. (8) describes the cutting force $F_{\mathrm{c}}$ and Eq. (9) the surface roughness Ra.

$F_{\mathrm{c}}=215.888 \times v_{\mathrm{c}}^{0.398651} \times f^{0.0336374} \times a_{\mathrm{p}}^{0.706277}$

$\mathrm{Ra}=3.455868 \times v_{\mathrm{c}}^{0.182942} \times f^{0.946694} \times a_{\mathrm{p}}^{-0.44174}$

Equation (10) describes the first mathematical model of WC-Co turning taking into account the Co content in the material structure. In the case of the constant coefficient determination for equations, the same algorithm as in the case of the previous equations was used. The difference occurs in the input equation.

$F_{\mathrm{c}}=a \times f^{b} \times v_{\mathrm{c}}{ }^{c} \times{a_{\mathrm{p}}}^{d} \times \mathrm{Co}^{e}$

After determination of the constant coefficients $a, b, c, d$, and $e$, the following equations were obtained. Equation (11) describes the cutting force $F_{\mathrm{c}}$ :

$F_{\mathrm{c}}=1381.66 \times v_{\mathrm{c}}^{0.190208} \times f^{-0.48079} \times a_{\mathrm{p}}^{0.882778} \times \mathrm{Co}^{0.379094}$

Table 10 Comparison of the cutting force $F_{\mathrm{c}}[\mathrm{N}]$ values for the first type of the experimental model, obtained from Eqs. (6) and (8) and measurements for the same cutting data for the first and second shafts

\begin{tabular}{llllll}
\hline \multirow{2}{*}{ No. } & \multicolumn{2}{l}{ First shaft } & & & \multicolumn{2}{l}{ Second shaft } \\
\cline { 2 - 3 } \cline { 5 - 6 } & $F_{\text {c_exp }}$ & $F_{\text {c_calc }}$ & & $F_{\text {c_exp }}$ & $F_{\text {c_calc }}$ \\
\hline 1 & 435.6 & 435.9 & & 414.5 & 414.6 \\
2 & 274.9 & 318.5 & & 311.0 & 361.0 \\
3 & 318.3 & 275.1 & & 361.0 & 311.0 \\
4 & 264.0 & 264.3 & & 284.2 & 284.1 \\
5 & 374.5 & 225.5 & & 323.9 & 244.4 \\
6 & 278.4 & 286.4 & & 264.4 & 314.7 \\
7 & 180.9 & 127.1 & & 196.1 & 160.8 \\
8 & 196.0 & 203.9 & 219.2 & 214.6 \\
9 & 222.8 & 185.9 & 222.7 & 193.5 \\
\hline
\end{tabular}

Table 11 Comparison of the surface roughness $\mathrm{Ra}[\mu \mathrm{m}]$ values for the first type of the experimental model, obtained from Eqs. (7) and (9) and measurements for the same cutting data for the first and second shafts

\begin{tabular}{llllll}
\hline \multirow{2}{*}{ No. } & \multicolumn{2}{l}{ First shaft } & & & \multicolumn{2}{l}{ Second shaft } \\
\cline { 6 - 6 } \cline { 6 - 6 } & Ra_ex & Ra_calc & & Ra_exp & Ra_calc \\
\hline 1 & 2.1 & 2.09 & 1.9 & 1.86 \\
2 & 0.6 & 0.89 & & 0.9 & 0.91 \\
3 & 0.9 & 0.63 & & 1.2 & 1.21 \\
4 & 1.2 & 1.24 & & 1.2 & 1.52 \\
5 & 1.9 & 0.81 & & 2.0 & 1.92 \\
6 & 1.1 & 1.43 & & 1.0 & 1.12 \\
7 & 1.2 & 0.62 & & 1.0 & 1.17 \\
8 & 1.6 & 2.20 & 1.7 & 2.07 \\
9 & 2.0 & 1.68 & 2.7 & 2.64 \\
\hline
\end{tabular}

Equation (12) describes the surface roughness Ra:

$\mathrm{Ra}=4.26695 \times v_{\mathrm{c}}^{1.60466} \times f^{0.290834} \times a_{\mathrm{p}}^{-0.41552} \times \mathrm{Co}^{0.19511}$

A comparison of the cutting force $F_{\mathrm{c}}$ and roughness $\mathrm{Ra}$ values obtained from the mathematical Eqs. (6-9) and (11-12) with values got from the measurements for the assumed cutting data is shown in Tables 10, 11, and 12 and Figs. 12, 13 , and 14.

Table 12 Comparison of the cutting force $F_{\mathrm{c}}[\mathrm{N}]$ and surface roughness $\mathrm{Ra}[\mu \mathrm{m}]$ values of the first experimental model, obtained from Eqs. (11) and (12) and measurements for the same cutting data, taking type of material into account

\begin{tabular}{lllll}
\hline No. & $F_{\text {c_exp }}$ & $F_{\text {c_calc }}$ & $R a_{\text {exp }}$ & $R a_{\text {calc }}$ \\
\hline 1 & 435.6 & 447.2 & 2.10 & 2.09 \\
2 & 274.9 & 449.7 & 0.63 & 0.627 \\
3 & 318.3 & 587.1 & 0.93 & 1.02 \\
4 & 264.0 & 352.6 & 1.24 & 1.33 \\
5 & 374.5 & 455.5 & 1.99 & 1.986 \\
6 & 278.4 & 285.8 & 1.18 & 0.79 \\
7 & 180.9 & 243.4 & 1.26 & 0.81 \\
8 & 196.0 & 187.3 & 1.55 & 1.83 \\
9 & 222.8 & 228.7 & 2.01 & 2.82 \\
10 & 414.5 & 368.5 & 1.90 & 1.902 \\
11 & 311.0 & 370.5 & 0.92 & 0.57 \\
12 & 361.0 & 483.7 & 1.22 & 0.92 \\
13 & 284.2 & 290.5 & 1.21 & 1.209 \\
14 & 323.9 & 375.3 & 1.99 & 1.80 \\
15 & 264.4 & 235.5 & 1.00 & 0.71 \\
16 & 196.1 & 200.5 & 1.08 & 0.74 \\
17 & 219.2 & 154.3 & 1.66 & 1.67 \\
18 & 222.7 & 188.4 & 2.67 & 2.56 \\
\hline
\end{tabular}




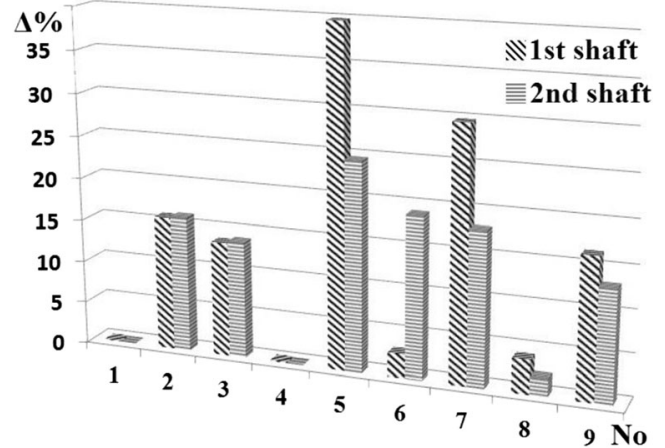

Fig. 12 Differences between experimental and calculation values

For the first model, the biggest error of the cutting force $F_{\mathrm{c}}$ value for the first shaft with contents of $25 \mathrm{wt} \%$ Co for the surface " 5 " equals $39 \%$ relative to the measured value. In the case of the shaft with contents of $15 \mathrm{wt} \% \mathrm{Co}$, the biggest error equals $24 \%$.

The biggest error of the surface roughness for the first shaft equals $59 \%$ relative to the measured value; for the second shaft, the biggest error equals $26 \%$ and is similar to the $F_{\mathrm{c}}$ cutting force.

In the case of the experimental model taking into account the type of material, the errors do not exceed a value of $30 \%$ for the cutting force $F_{\mathrm{c}}$ and $38 \%$ for the surface roughness Ra. Equation (11) should be used for predicting values of the cutting force $F_{\mathrm{c}}$. In the case of the estimating values of the roughness Ra, Eqs. (7) and (9) for the first model type should be used.

Figures $15,16,17$, and 18 present the examples of diagrams according to the mathematical equations describing the first type of experimental model. The cutting force $F_{\mathrm{c}}$ in the function of the depth of cut $a_{\mathrm{p}}$ and cutting speed $v_{\mathrm{c}}$ for the first shaft are shown in Fig. 15. Figure 17 presents the surface roughness Ra in the function of the depth of cut $a_{\mathrm{p}}$ and cutting speed $v_{\mathrm{c}}$ for the second shaft. The cutting speed increase influences on the cutting force increase (Fig. 16). The same tendency is observed for the increase of the depth of cut and

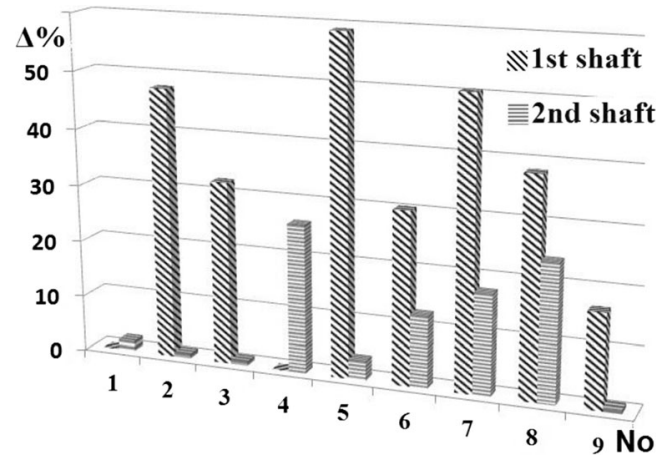

Fig. 13 Differences between experimental and calculation values

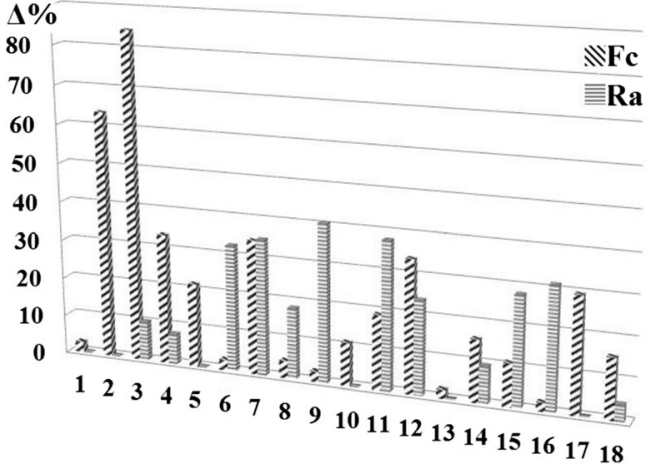

Fig. 14 Differences between experimental and calculation values

feed. The surface roughness decreases when the depth of cut increases and cutting speed decreases.

The cutting force $F_{\mathrm{c}}$ in the function of the depth of cut $a_{\mathrm{p}}$ and Co content is presented in Figs. 25, 26, and 27 in Appendix 3. The increase of Co content influences the slight increase of the cutting force.

The following notations are used for Figs. 16 and 18: $1\left(v_{\mathrm{c}}=10 \mathrm{~m} / \mathrm{min}, a_{\mathrm{p}}=0.35 \mathrm{~mm}\right), 2(10 ; 0.5), 3(15 ; 0.2)$, $4(15 ; 0.35), 5(15 ; 0.5), 6(20 ; 0.2), 7(20 ; 0.35)$, and 8 $(20 ; 0.5)$.

4.2 Second type of experimental model based on the modified RSM method

For the second type of the experimental model, the modified response surface methodology (RSM) was used. In the standard version of RSM, the equation describing the investigated phenomenon has the form [33-37]:

$y=\beta_{0}+\sum_{i=0}^{n} \beta_{i} x_{i}+\sum_{i=0}^{n} \beta_{i i} x_{i i}^{2}+\sum_{i<j}^{n} \beta_{i j} x_{i} x_{j}$

In our case, the required number of $y$ values should be 10 . There are only nine results of the cutting force $F_{\mathrm{c}}$ and surface roughness $\mathrm{Ra}$ in the case of the Taguchi method usage in the investigation for the first and second shafts. For that reason,

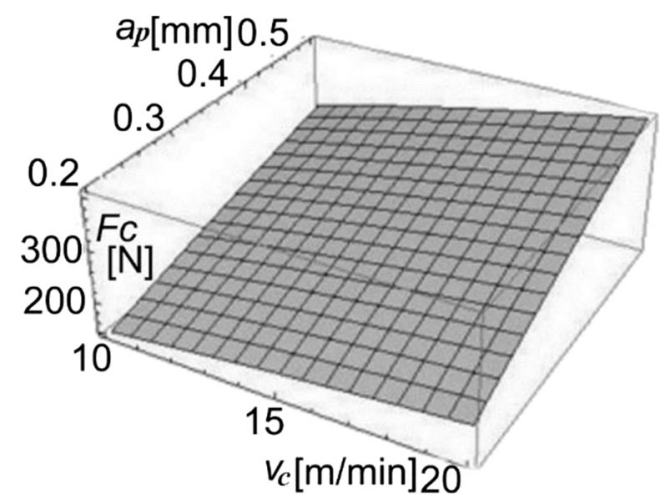

Fig. 15 Cutting force $F_{\mathrm{c}}$ in the function of depth of cut $a_{\mathrm{p}}$ and cutting speed $v_{\mathrm{c}}$ for feed $f=0.153 \mathrm{~mm} / \mathrm{rev}$ for the first shaft 


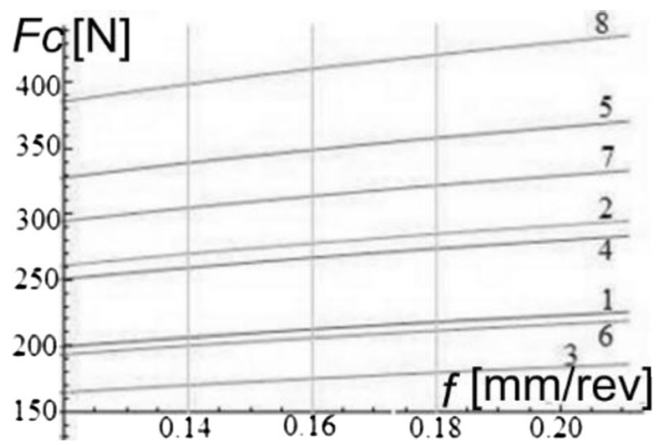

Fig. 16 Cutting force $F_{\mathrm{c}}$ in the function of feed $f$ for different values of the other cutting data $\left(v_{\mathrm{c}} ; a_{\mathrm{p}}\right)$ for the first shaft

Eq. (13) is modified to omit the impact of correlations between cutting speed and feed for the cutting force $F_{\mathrm{c}}$. In the case of roughness $\mathrm{Ra}$, the correlation between feed and depth of cut was omitted. Omission of these correlation results from analysis of the variance ANOVA, because the influence of those parameters are very small relative to the rest of the correlations between two parameters. In the case of the cutting force $F_{\mathrm{c}}$, the depth of cut has the greatest impact, and therefore, only correlation between this parameter with others was included. In the case of the surface roughness $\mathrm{Ra}$, the greatest impact has the cutting speed, and therefore, the correlation of the cutting speed with two other was taken into account.

The steps of the experimental model construction, describing the predicted cutting force $F_{\mathrm{c}}$ values for the first shaft based on the modified RSM equations (Fig. 1), are presented as follows. Basing on Eq. (13) and values from Tables 3 and 4, the following equation can be written (14):

$$
\begin{aligned}
F_{\mathrm{c}}= & \beta_{0}+\beta_{1} v_{c}+\beta_{2} f+\beta_{3} a_{p}+\beta_{4} v_{c}^{2}+\beta_{5} f^{2}+\beta_{6} a_{p}^{2} \\
& +\beta_{7} a_{p} v_{c}+\beta_{8} a_{p} f
\end{aligned}
$$

where $F_{c}$ is the estimated value of the cutting force and $\beta_{0}$ $\ldots \beta_{8}$ are the constant coefficients

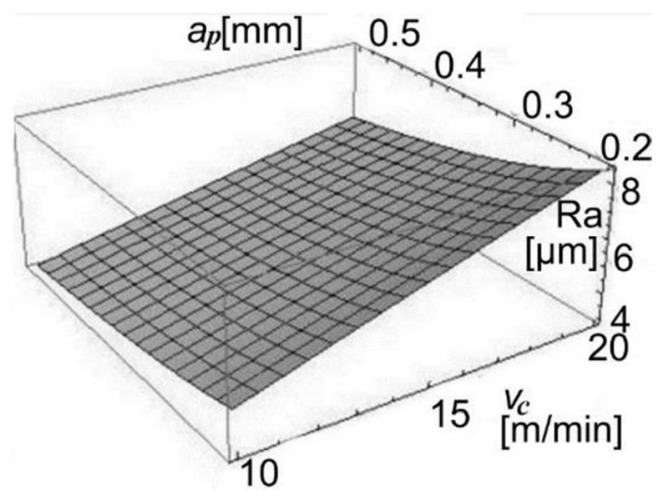

Fig. 17 Surface roughness $\mathrm{Ra}$ in the function of depth of cut $a_{\mathrm{p}}$ and cutting speed $v_{\mathrm{c}}$ for feed $f=0.153 \mathrm{~mm} / \mathrm{rev}$ for the second shaft

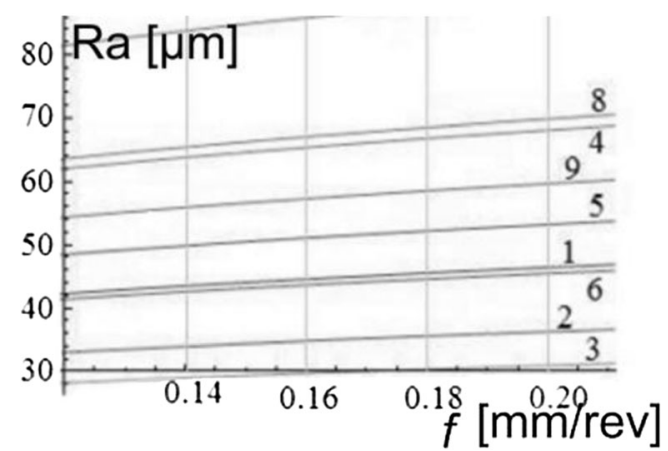

Fig. 18 Surface roughness Ra in the function of feed $f$ for different values of the other cutting data $\left(v_{\mathrm{c}} ; a_{\mathrm{p}}\right)$ for the second shaft

Substituting the above equation into the Mathematica software, the values of the $\beta$ coefficients were calculated (Eq. 15).

$$
\begin{aligned}
F_{\mathrm{c}}= & 371.768+169.628 v_{\mathrm{c}}-22323.9 f+1267.03 a_{\mathrm{p}} \\
& -3.75619 v_{\mathrm{c}}^{2}+54485.8 f^{2}-1521.41 a_{\mathrm{p}}^{2} \\
& +17273.3 a_{\mathrm{p}} v_{\mathrm{c}}-161.708 a_{\mathrm{p}} f
\end{aligned}
$$

In the case of the equation, describing the surface roughness $\mathrm{Ra}$, the input equation has a different form than equation describing the force $F_{\mathrm{c}}$. The other correlations between the cutting data are selected to the equations, based on the results, obtained by the ANOVA analysis. The input equation is as follows (16):

$$
\begin{aligned}
\mathrm{Ra}= & \beta_{0}+\beta_{1} v_{\mathrm{c}}+\beta_{2} f+\beta_{3} a_{\mathrm{p}}+\beta_{4} v_{\mathrm{c}}^{2}+\beta_{5} f^{2}+\beta_{6} a_{\mathrm{p}}^{2} \\
& +\beta_{7} v_{\mathrm{c}} f+\beta_{8} v_{\mathrm{c}} a_{\mathrm{p}}
\end{aligned}
$$

where $\mathrm{Ra}$ is the estimated value of roughness and $\beta_{0} \ldots \beta_{8}$ are the constant coefficients,

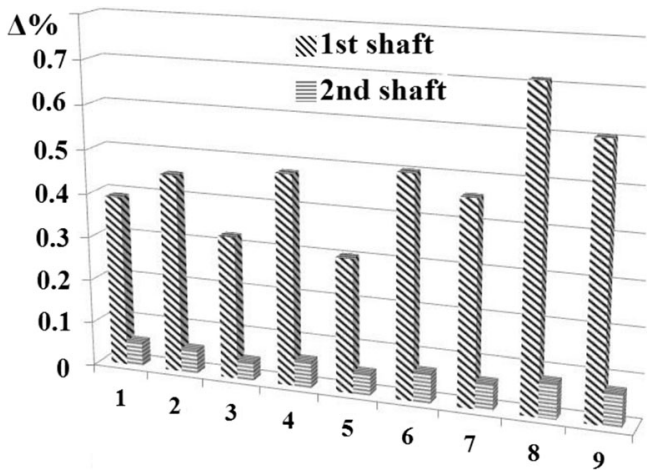

Fig. 19 Differences between experimental and calculation values of the cutting force $F_{\mathrm{c}}$ for the second type of the model, obtained from the Eqs. (15) and (18) and measurements for the same cutting data for the first and second shafts 


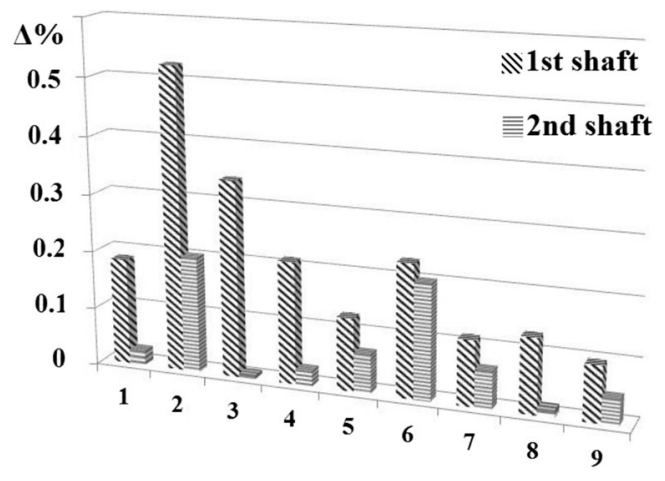

Fig. 20 Differences between experimental and calculation values of the surface roughness Ra for the second type of the model, obtained from the Eqs. (17) and (19) and measurements for the same cutting data for the first and second shafts

After calculation of the equations' system in the Mathematica software, the following values of the $\beta$ coefficients were substituted in Eq. 17.

$$
\begin{aligned}
\mathrm{Ra}= & 1.89338-0.26644 v_{\mathrm{c}}+44.5025 f-16.0481 a_{\mathrm{p}} \\
& +0.008333 v_{\mathrm{c}}^{2}-63.2094 f^{2}+9.25926 a_{\mathrm{p}}^{2}-v_{\mathrm{c}} f \\
& +0.555556 v_{\mathrm{c}} a_{\mathrm{p}}
\end{aligned}
$$

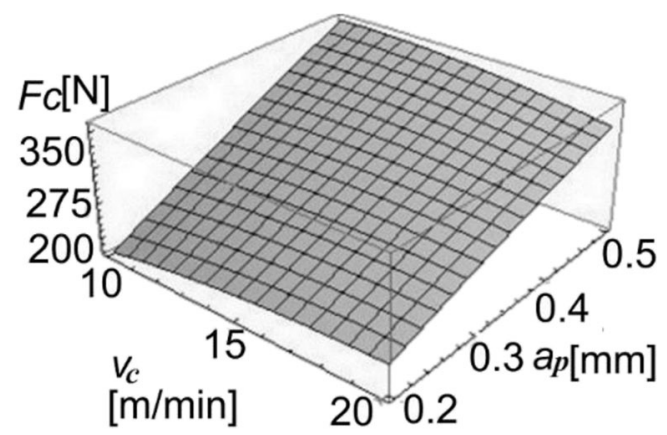

Fig. 21 Cutting force $F_{\mathrm{c}}$ in the function of depth of cut $a_{\mathrm{p}}$ and cutting speed $v_{\mathrm{c}}$ for feed $f=0.153 \mathrm{~mm} / \mathrm{rev}$ for the second shaft

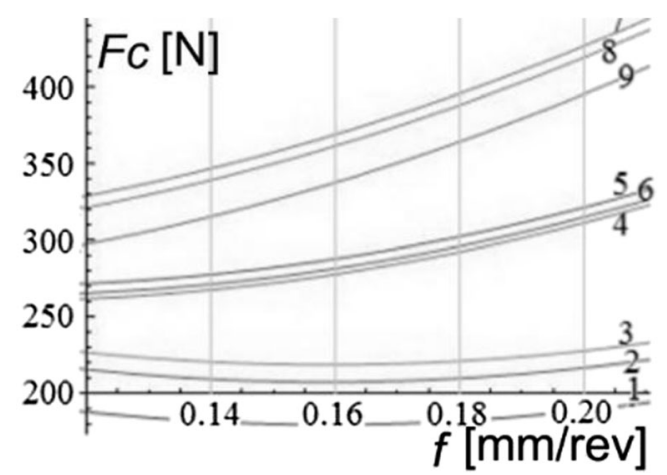

Fig. 22 Cutting force $F_{\mathrm{c}}$ in the function of feed $f$ for the different values of the other cutting data $\left(v_{\mathrm{c}} ; a_{\mathrm{p}}\right)$ for the second shaft

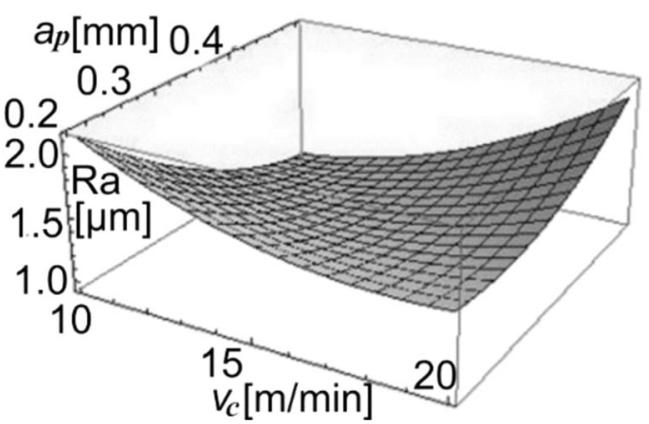

Fig. 23 Surface roughness Ra in the function of depth of cut $a_{\mathrm{p}}$ and cutting speed $v_{\mathrm{c}}$ for feed $f=0.153 \mathrm{~mm} / \mathrm{rev}$ for the first shaft

For the second shaft, the $F_{\mathrm{c}}$ and Ra can be calculated from Eqs. (18) and (19).

$$
\begin{aligned}
F_{\mathrm{c}}= & 155.08+18.3674 v_{\mathrm{c}}-2538.71 f+323.226 a_{\mathrm{p}} \\
& -0.32753 v_{\mathrm{c}}^{2}+5453.38 f^{2}-150.37 a_{\mathrm{p}}^{2}+4033.33 a_{\mathrm{p}} v_{\mathrm{c}} \\
& -23.3556 a_{\mathrm{p}} f \\
\mathrm{Ra}= & 10.8535+0.033933 v_{\mathrm{c}}-317.495 f+82.9622 a_{\mathrm{p}} \\
& -0.005 v_{\mathrm{c}}^{2}+736.36 f^{2}-67.6 a_{\mathrm{p}}^{2}-6.4 v_{\mathrm{c}} f-2.50133 v_{\mathrm{c}} a_{\mathrm{p}}
\end{aligned}
$$

Figures 19 and 20 present the comparison of the cutting force $F_{\mathrm{c}}$ and surface roughness Ra values for the second type of the experimental model, obtained from Eqs. $(15,17-19)$ and measurements for the same cutting data for the first and second shafts.

The errors between calculated and measured values for the second experimental model do not exceed $1 \%$.

Figures 21, 22, 23, and 24 present the examples of diagrams according to the mathematical equations describing the second type of the experimental model. The cutting force $F_{\mathrm{c}}$ in the function of the depth of cut $a_{\mathrm{p}}$ and cutting speed $v_{\mathrm{c}}$ for the second shaft are shown in Figs. 21 and 22. Figure 23 presents the surface roughness $\mathrm{Ra}$ in the function of the depth of cut $a_{\mathrm{p}}$

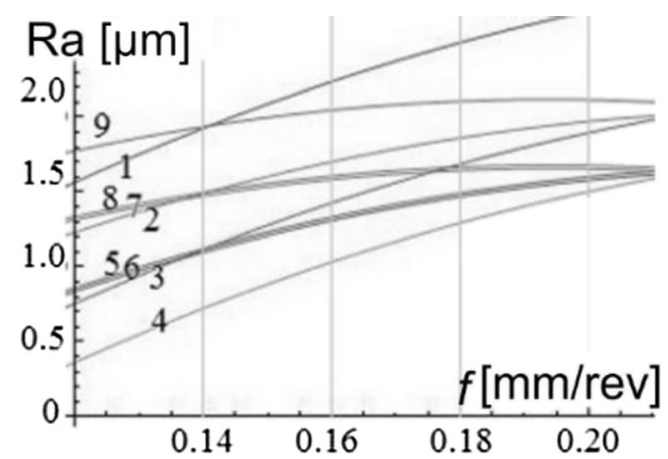

Fig. 24 Surface roughness Ra in the function of feed $f$ for the different values of the other cutting data $\left(v_{\mathrm{c}} ; a_{\mathrm{p}}\right)$ for the first shaft 
Fig. 25 The function of depth of cut $a_{\mathrm{p}}$ and Co content for feed $f=$ $0.153 \mathrm{~mm} / \mathrm{rev}$ and cutting speed $v_{\mathrm{c}}=15 \mathrm{~m} / \mathrm{min}$ for a the cutting force $F_{\mathrm{c}}$ and $\mathbf{b}$ the surface roughness $\mathrm{Ra}$
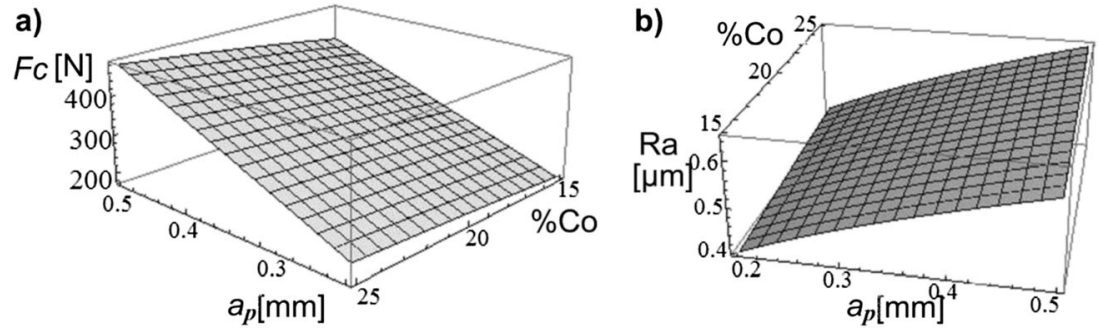

Fig. 26 The function of feed $f$ for the different values of the other cutting data $\left(v_{\mathrm{c}} ; a_{\mathrm{p}}\right)$ and two types of material for a the cutting force $F_{\mathrm{c}}$ and $\mathbf{b}$ the surface roughness $\mathrm{Ra}$
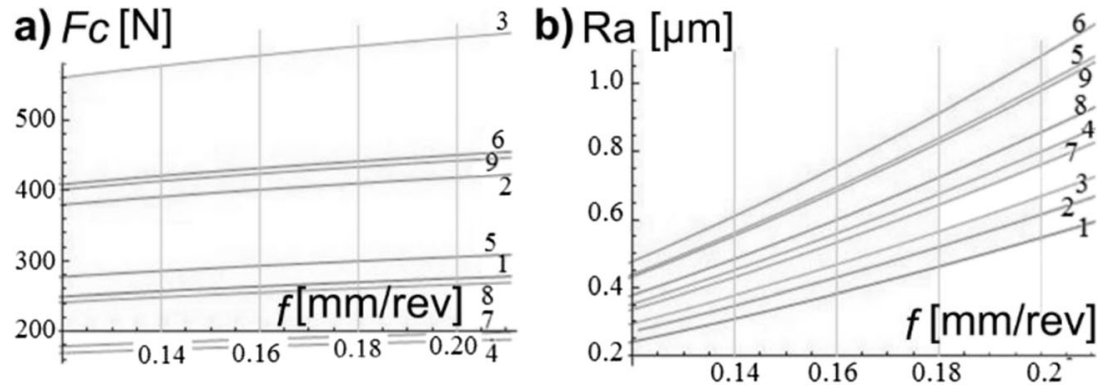

and cutting speed $v_{\mathrm{c}}$ for the first shaft. The cutting speed increase influences the cutting force increase. The same tendency is observed for the increase of the depth of cut and feed. Surface roughness decreases when depth of cut and cutting speed increase.

The following notations are used for Figs. 22 and 24: 1 $(10 \mathrm{~m} / \mathrm{min} ; 0.2 \mathrm{~mm}), 2(10 \mathrm{~m} / \mathrm{min} ; 0.35 \mathrm{~mm}) 3(10 \mathrm{~m} / \mathrm{min}$; $0.5 \mathrm{~mm}) 4$ (15 m/min; $0.2 \mathrm{~mm}), 5$ (15 m/min; $0.35 \mathrm{~mm}) 6$ $(15 \mathrm{~m} / \mathrm{min}$; $0.5 \mathrm{~mm}), 7$ (20 m/min; $0.2 \mathrm{~mm}), 8(20 \mathrm{~m} / \mathrm{min}$; $0.35 \mathrm{~mm})$, and $9(20 \mathrm{~m} / \mathrm{min} ; 0.5 \mathrm{~mm})$

\section{Conclusion}

In present research, the analysis of super hard material machining such as sintered carbides WC-Co with different Co content in the material structure is shown. In studies, the main attention has been focused on the main cutting force component $F_{\mathrm{c}}$ and the surface roughness parameter Ra values, depending on the cutting data $\left(v_{\mathrm{c}}, f, a_{\mathrm{p}}\right)$ (Figs. 25, 26, and 27 in Appendix 3).
In the comparison of WC-Co with two different Co contents ( 15 and $25 \mathrm{wt} \%$ ), in terms of the cutting force $F_{\mathrm{c}}$, there was no clear effect of Co content on the turning process. The lowest $F_{\mathrm{c}}$ values were obtained for the same cutting data. When machining material with less content of Co, higher $F_{\mathrm{c}}$ values for the same cutting data were generated. A similar relationship was noticed in the case of the cutting data for which the lowest surface roughness Ra values were obtained. Higher surface roughness values were measured for the material with lower Co content in its structure

The ANOVA analysis showed the biggest percentage influence of the depth of cut and cutting speed on the $F_{\mathrm{c}}$ and $\mathrm{Ra}$ parameters. In the case of cutting force, the depth of cut has the percentage effect equals 59 and $80 \%$ for $25 \mathrm{wt} \%$ Co and $15 \mathrm{wt} \% \mathrm{Co}$, respectively. In the case of surface roughness, the cutting speed has the percentage effect equals 77.5 and $78 \%$ for $25 \mathrm{wt} \%$ Co and $15 \mathrm{wt} \% \mathrm{Co}$, respectively.

During turning of the sintered carbides with $10 \mathrm{wt} \% \mathrm{Co}$, the required range of the depth of cut was exceeded. The big sizes of chips were obtained as a result of chipping process.

The increase of the feed and depth of cut values influences the increase of the cutting force. The lowest values of the force
Fig. 27 The function of cutting speed $v_{\mathrm{c}}$ for the different values of the other cutting data $\left(f ; a_{\mathrm{p}}\right)$ and two types of material for a the cutting force $F_{\mathrm{c}}$ and $\mathbf{b}$ the surface roughness $\mathrm{Ra}$

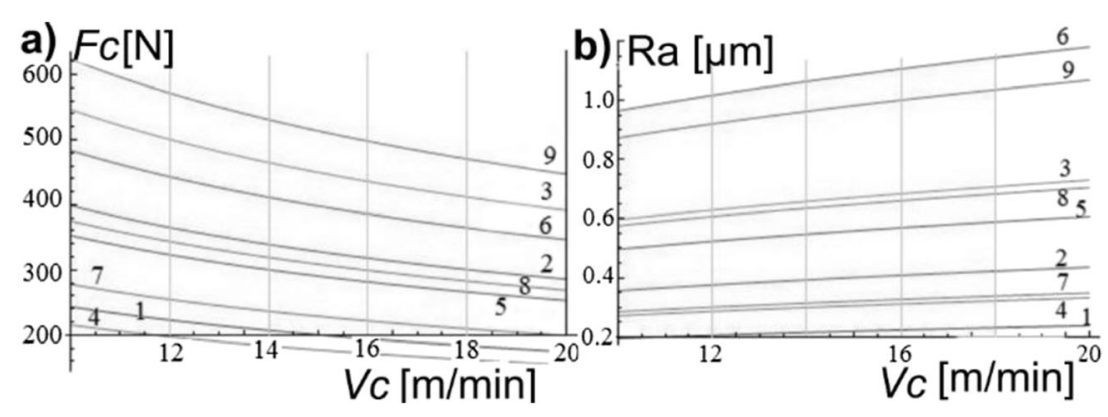


$F_{\mathrm{c}}$ were obtained for the material with the lowest content of Co in the structure. The other situation takes place in the case of the surface roughness. The worst surface quality was obtained for the bigger feed values and lower depth of cut and for material with the lowest content of $\mathrm{Co}$. It is probably a result of adhesion phenomenon between the work piece material and the tool, bigger at high content of $\mathrm{Co}$ and high hardness of the material.

Two different methods for the design of experimental models are shown in this paper. The first model is based on the power function; the second is based on the polynomial function according to modified RSM equations. The obtained equations allow the prediction of approximate values of $F_{\mathrm{c}}$ or $\mathrm{Ra}$ for a given type of sintered carbides and cutting data. Further studies will focus on tool wear research during machining, to determine a wear coefficient and its influence on the cutting force $F_{\mathrm{c}}$ and surface roughness Ra values.

\section{Appendix 1}

Usage types of the $\mathrm{S} / \mathrm{N}$ ratio (signal to noise) [24-31]:

1. Smaller-the-better, minimize certain undesirable characteristics of the research product:

$$
S / N=-10 \log _{10}\left[(1 / n) \times \sum\left(y_{i}^{2}\right)\right]
$$

for $i=1$ to $n$, where $n$ is the number of measurements, and $y_{i}$ is the $i$ th observed value of the response.

2. Nominal-the-best, the fixed value of the signal (the variability around this value can be regarded as the result of the noise):

$$
\begin{aligned}
& S / N=-10 \log _{10}\left(\text { Average }^{2} / \text { Variance }\right) \\
& \text { for } i=1 \text { to } n .
\end{aligned}
$$

3. Larger-the-better, the efficiency of the product:

$$
S / N=-10 \log _{10}\left[(1 / n) \times \sum\left(1 / y_{i}^{2}\right)\right]
$$

$$
\text { for } i=1 \text { to } n \text {. }
$$

\section{Appendix 2}

Degree of factor freedom

$(\mathrm{df})_{A}=K_{A}-1$, where $K_{A}$ is a number of levels
The total degree of the results freedom

$(\mathrm{df})_{T}=N-1$, where $N$ is a number of experiments

The degree of freedom for error variance

$(\mathrm{df})_{e}=(\mathrm{df})_{T}-\sum(\mathrm{df})_{\text {factor, }}$, where $\sum(\mathrm{df})_{\text {factor }}$ is a sum of degree of factors freedom

Sum of square for factor $\boldsymbol{A}$ at level $\boldsymbol{K}$

$S S_{A}=\sum_{i=1}^{k_{A}} n_{A i}\left(A_{i}-\bar{T}\right)^{2}=\left[\sum_{i=1}^{k_{A}}\left(\frac{A_{i}^{2}}{n_{A i}}\right)\right]-\frac{T^{2}}{N}$, where $N$ is a total number of experiences, $n_{A i}$ is the number of levels, and $A_{i}$ is the sum of cutting forces or surface roughness in level $i$ of factor $A$

The sum of squares of error

$\mathrm{SS}_{e}=\sum_{j=1}^{k_{A}} \sum_{i=1}^{n_{A j}}\left(y_{i}-\bar{A}_{j}\right)^{2}$ or $\mathrm{SS}_{e}=\mathrm{SS}_{T}-\sum \mathrm{SS}_{\text {factor }}$

$\alpha$-level of significance represents the probability of the null hypothesis $H_{0}$ rejection. It is likely that the statistics will have at least the same value that observed one, assuming that $H_{0}$ is true $[24,26,27,29-31]$.

\section{Appendix 3}

The following notations are used for Fig. 26: $1\left(v_{\mathrm{c}}=10 \mathrm{~mm} /\right.$ $\min ; a_{\mathrm{p}}=0.2 \mathrm{~mm} ; \mathrm{wt} \%$ Co 25$), 2(10 ; 0.35 ; 25), 3(10 ; 0.5$; 25), 4. (15;0.2; 15), $5(15 ; 0.35 ; 15), 6(15 ; 0.5 ; 15), 7(20 ; 0.2$; $25), 8(20 ; 0.35 ; 15)$, and $9(20 ; 0.5 ; 25)$.

The following notations are used for Fig. $27: 1(f=0.105 \mathrm{~mm} /$ rev; $a_{\mathrm{p}}=0.2 \mathrm{~mm} ; \mathrm{wt} \%$ Co 25$), 2(0.105 ; 0.35 ; 25), 3$ (0.105; 0.5 ; 25), $4(0.153 ; 0.2 ; 15), 5(0.153 ; 0.35 ; 15), 6(0.153 ; 0.5 ; 15), 7$ $(0.211 ; 0.2 ; 25), 8(0.211 ; 0.35 ; 15)$, and $9(0.211 ; 0.5 ; 25)$.

Open Access This article is distributed under the terms of the Creative Commons Attribution License which permits any use, distribution, and reproduction in any medium, provided the original author(s) and the source are credited.

\section{References}

1. Fratila D (2013) Sustainable manufacturing through environmentally-friendly machining. In: Davim JP (ed) Green manufacturing process and systems materials forming, machining and tribology. Springer, Berlin Heidelberg, pp 1-21 
2. de Lacalle LN L, Lamikiz A, de Larrinova FJ, Azkona I (2011) Advanced cutting tools. In: Davim J (ed) Machining of hard materials. Springer, London, pp 33-85

3. Newman ST, Nassehi A, Imani-Asrai R, Dhokia V (2012) Energy efficient process planning for CNC machining. CIRP J Manuf Sci Technol 5:127-136. doi:10.1016/j.cirpj.2012.03.007

4. Krajnik P, Kopac J (2004) Modern machining of die and mold tools. J Mater Process Technol 157-157:543-552. doi:10.1016/j.jmatprotec. 2004.07.146

5. Dobrzański LA (2002) Podstawy nauki o materiałach i metaloznawstwo. Materiały inżynierskie z podstawami projektowania materiałowego. WNT, Warszawa

6. Zak Fang Z, Wang X, Ryu T, Hwang KS, Sohn HY (2009) Synthesis, sintering, and mechanical properties of nanocrystalline cemented tungsten carbide - a review. Int J Refract Met Hard 27:288-299. doi:10.1016/j.ijrmhm.2008.07.011

7. Khechba M, Hanini F, Halimi R (2011) Study of structural and mechanical properties of tungsten carbides coatings. Nat Technol 5: 9-11

8. Jaworska L (2007) Diament, otrzymywanie i zastosowanie w obróbce skrawaniem. WNT, Warszawa

9. Arsecularatne JA, Zhang LC, Montross C (2006) Wear and tool life of tungsten carbide, PCBN and PCD cutting tools. Int J Mach Tools Manuf 46:482-491. doi:10.1016/j.ijmachtools.2005.07.015

10. Byrne G, Dornfeld D, Denkena B (2003) Advancing cutting technology. CIRP Ann Manuf Technol 52:483-507

11. Cook MW, Bosson PK (2000) Trends and recent developments in the material manufacture and cutting tool application of polycrystalline diamond and polycrystalline cubic boron nitride. Int J Refract Met Hard 18:147-152

12. Jackson MJ, Ahmed W (2009) Machining of brittle materials using nanostructured diamond tools. In: Jackson MJ, Morrell JS (eds) Machining with nanomaterials. Springer, US, pp 1-30

13. Bogus A, Gebeshuber IC, Pauschitz A, Roy M, Haubner R (2008) Micro-and nanomechanical properties of diamond film with various surface morphologies. Diam Relat Mater 17:1998-2004. doi:10. 1016/j.diamond.2008.06.010

14. Mitura S, Mitura K, Niedzielski P, Luda P, Danilenko V (2006) Nanocrystalline diamond, its synthesies, properties and applications. J Achiev Mater Manuf Eng 16:9-16

15. Belmonte B, Ferro P, Fernandes AJS, Costa FM, Sacramento J, Silva RF (2003) Wear resistant CVD diamond tools for turning for sintered hardmetals. Diam Relat Mater 12:738-743

16. Belmonte M, Oliveira FJ, Sacramento J, Fernandes AJS, Silva RF (2004) Cutting forces evolution with tool wear in sintered hardmetal turning with CVD diamond. Diam Relat Mater 13:843-847. doi:10. 1016/j.diamond.2003.11.018

17. Almeida FA, Oliveira FJ, Sousa M, Frenandes AJS, Sacrameto J, Silva RF (2005) Machining hardmetal with CVD diamond direct coated ceramic tools: effect of tool edge geometry. Diam Relat Mater 14:651-656. doi:10.1016/j.diamond.2004. 09.002

18. Sung-jung H (2004) Micro cutting of tungsten carbides with sem direct observation method. Int J KSME 18-5:770-779

19. Almeida FA, Fernandes AJS, Silva RF, Oliveira FJ (2006) Resharpenable thick CVD diamond-coated $\mathrm{Si}_{3} \mathrm{~N}_{4}$ tools for hardmetal turning. Surf Coat Technol 201:1776-1782. doi:10.1016/j.surfcoat. 2006.03.005
20. Sung Jung H (2008) Environmentally conscious hard turning of cemented carbide materials on the basis of micro-cutting in SEM: stressing four kinds of cemented carbides with PCD tools. J Mech Sci Technol 22:1383-1390. doi:10.1007/s12206-008-0411-z

21. Sung Jung H (2009) Environmentally conscious hard turning of cemented carbide materials on the basis of micro-cutting in SEM (2nd report): stress turning with three kinds of cutting tools. J Mech Sci Technol 23:1959-1966. doi:10.1007/s12206009-0512-3

22. Almeida FA, Fernandes AJS, Oliveira FJ, Silva RF (2009) Semiorthogonal turning of hardmetal with CVD diamond and PCD inserts at different cutting angles. J Vac Sci Technol 83:1218-1223. doi:10. 1016/j.vacuum.2009.03.029

23. Zhong ZW, Peng ZF, Liu N (2007) Surface roughness characterization of thermally sprayed and precision machined WC-Co and Alloy625 coatings. Mater Charact 28:997-1005. doi:10.1016/j.matchar. 2007.05.010

24. Inform to www.statsoft.com

25. Xueping Z, Erwei G, Liu CR (2009) Optimization of process parameter of residual stresses for hard turned surfaces. J Mater Process Technol 209:4286-4291. doi:10.1016/j.jmatprotec. 2008.10.011

26. Muthukrishnan N, Davim JP (2009) Optimization of machining parameters of $\mathrm{Al} / \mathrm{SiC}-\mathrm{MMC}$ with ANOVA and ANN analysis. J Mater Process Technol 209:225-232. doi:10.1016/j.jmatprotec. 2008.01.041

27. Lazarevic D, Madic M, Jankovic P, Lazarevic A (2011) Surface roughness minimization of polyamide PA- 6 turning by Taguchi method. J Prod Eng 15-1:29-32

28. Krishankant, Taneja J, Bector M, Kumar R (2012) Application of Taguchi method of optimizing turning process by the effects of machining parameters. Int J Eng Adv Technol 2-1:263-274

29. Ramanujam R, Muthukrishnan N, Raju R (2011) Optimization of cutting parameters for turning $\mathrm{Al}-\mathrm{SiC}(10 \mathrm{p}) \mathrm{MMC}$ using ANOVA and grey relation analysis. Int J Precis Eng Manuf 12-4:651-656. doi:10. 1007/s12541-011-0084-x

30. Chomsamutr K, Jongprosithporn S (2012) optimization parameters of tool life model using the Taguchi approach and response surface methodology. Int J Comput Sci Issues 9-3:120-125

31. Gopalsamy BM, Mondal B, Ghosh S (2009) Taguchi method and ANOVA: an approach for process optimization of hard machining while machining hardened steel. J Sci Ind Res 68:685-695

32. Catalogue of tools for sintered carbides Mitsubishi company

33. Shah SC, Geroge PM (2012) Surface roughness modeling in precision turning of aluminium by polycrystalline diamond tool using response surface methodology. Int J Emerge Technol Adv Eng 2-5: $41-45$

34. Doniavi A, Eskandarzade M, Tahmasebian M (2007) Empirical modeling of surface roughness in turning of 1060 steel using factorial design methodology. J Appl Sci 7-17:2509-2513

35. Abhang LB, Hameedullah M (2012) Optimal machining parameters for achieving the desired surface roughness in turning of steel. J Eng Res 9-1:37-45

36. Bajic D, Jozic S, Podrug S (2010) Design of experiment's application in the optimization of milling process. METABK 49-2:123-126

37. Gowd GH, Reddy MG, Sreenivasulu B (2012) Empirical modeling of hard turning process of Inconel using response surface methodology. Int J EmergTechnol Adv Eng 2-10:498-504 